\title{
Modeling news-driven international business cycles
}

\author{
Paul Beaudry ${ }^{\mathrm{a}, \mathrm{b}}$, Martial Dupaigne ${ }^{\mathrm{c}}$, Franck Portier ${ }^{\mathrm{c}, *}$ \\ a University of British Columbia, Canada \\ b NBER, United States \\ c Toulouse School of Economics, France
}

\section{A R T I C L E I N F O}

\section{Article history:}

Received 30 November 2009

Revised 1 November 2010

Available online 4 December 2010

\section{JEL classification:}

E32

F41

Keywords:

Business cycles

Expectations

International fluctuations

News shocks

\begin{abstract}
A B S T R A C T
This paper reexamines the question of how to explain business cycle co-movements within and between countries. First, we present a simple flexible price models to illustrate how and why news shocks can generate robust positive co-movements in economic activity across countries. We also discuss under what conditions a two-sector version of the model generates appropriate business cycle patterns within countries. Second, we develop a quantitative two-country two-sector model that is capable of replicating news driven international business cycles. The model is a two-country extension of the closed economy model of Beaudry and Portier (2004), in which there are limited possibilities to reallocate factors between investment and consumption-good sectors.
\end{abstract}

(C) 2010 Published by Elsevier Inc.

\section{Introduction}

The macroeconomic literature often emphasizes the role of the expectations of investors in driving business cycles. These ideas go back at least to A.C. Pigou and J.M Keynes. One embodiment of this literature stresses the role of expectations regarding future productivity growth in creating fluctuations. This line of research is supported by empirical evidence suggesting that Total Factor Productivity improvements are reflected in stock prices fluctuations many quarters before they actually arise in measured TFP (see Beaudry and Portier, 2005, 2006; Haertel and Lucke, 2007), and that news shocks are an important component of business cycles (Schmitt-Grohé and Uribe, 2008; Beaudry and Lucke, 2009). Theoretical and quantitative explanations of how news shocks affect economic activity have been investigated within a closed economy setups in a set of recent papers (Beaudry and Portier, 2004; Beaudry et al., 2006; Christiano et al., 2008; Jaimovich and Rebelo, 2008; Den Haan and Kaltenbrunner, 2009). In this paper, we examine the extent to which such changes in expectations, as captured by "news shocks", helps understanding international business cycle fluctuations.

Business Cycles are known to display two important and quite distinctive features. The first one, that we label "National Business Cycles" (hereafter $N B C$ ) is the fact that macroeconomic aggregates (consumption, investment, output, worked hours) are positively correlated. The second one, that we label "International Business Cycles" (hereafter $I B C$ ) is the fact that these same aggregates are pairwise correlated across countries. These two set of facts are well documented in the literature (see for example Ambler et al., 2004), and happen to be quite challenging to replicate for standard equilibrium macroeconomic theory. At first sight, the challenge seems easy to meet. As shown by Backus, Kehoe and Kydl (1995) (hereafter BKK),

\footnotetext{
We thank the referee and the editor for their comments, as well as Fabrice Collard, Luca Dedola, Patrick Fève and Laura Veldkamp for helpful discussions. This research is part of the NDBCA project (ANR-06-BLAN-0248) financed by the French ANR. Franck Portier is also affiliated to CEPR.

* Corresponding author.

E-mail address: fportier@cict.fr (F. Portier).
} 
a two country Real Business Cycle model in the tradition of Kydland and Prescott (1982) can display both NBC and IBC properties when perturbed by technological shocks. Note however that this result crucially relies on two assumptions: first that technological shocks are surprises and second that they are common across countries. These two assumptions, which are needed to generate NBC and IBC are questionable. First, technological improvements appear forecastable to a large extent, as Beaudry and Portier (2006) have shown that (permanent) technology improvements likely diffuse only slowly over time. Second, technological shocks are not common nor highly correlated across countries as shown in Ambler et al. (2004). High correlation is needed in BKK type of models to replicate IBC facts, as purely local technological shocks lead to the reallocation of capital across countries and therefore generate negatively correlated cycles across countries.

As technology shocks appear insufficiently "global" to reproduce IBC facts, other shocks or market frictions seems to be needed for business cycles synchronization across countries to arise, as illustrated by Wen (2007). We show in this paper that news shocks offer a driving force that can generate cross-country synchronization of activity even in a frictionless and flex-price economy. The key insight to understand the result is that, because news shocks are common knowledge and do not affect current fundamentals, they act as a common "demand" shock. In Section 1 of this paper, we formally prove the synchronizing effect of news. In Section 2, we propose a frictionless two-country quantitative model that builds on Beaudry and Portier (2004) closed economy model, and that is able to generate news-driven IBC. We also clarify why typical international RBC models fail generating news driven international business cycles. Section 3 concludes.

\section{The cross-country effects of news shocks}

In this section, we study the consequences of country-specific news shock in multi-country models. Even when news are about the fundamentals of only in one country, the news shock changes expectations in all countries and is therefore a powerful source of synchronization in activity between countries. We make this claim most clearly in a setup with full capital mobility, where the equilibrium allocations display perfect symmetry across country after the arrival of new information but before the realization of the change in fundamentals.

Although news shocks generate symmetric response between countries, we also show that in two-country models with one sector and full capital mobility, they create opposite movements of consumption one the one side and investment and worked hours on the other side. In one-sector economies, news shock therefore cannot be an important driver of the business cycle. We then present a version of a two-sector two-country models where news shocks can increase investment and hours on impact without decreasing consumptions, therefore creating business cycle like fluctuations.

\subsection{A one-sector setup with full capital mobility}

\subsubsection{The setup}

The economy we study is composed of two countries, $A$ and $B$. Country $A$ hosts a fraction $0<\pi<1$ of world population.

Both countries produce an homogeneous final good, which can be devoted to consumption or to augment the world stock of capital per capita $K_{t}$. This good is produced with the same concave technology in both countries, $F\left(K_{J, t}, H_{J, t} ; \theta_{J, t}\right)$, with strictly positive and strictly decreasing marginal products. $H_{J, t}$ and $K_{J, t}$ respectively denote the labor and capital input per capita used in country $J$ at date $t$. The technology index $\theta_{J, t}$ has a forecastable component and may have a non-forecastable one, but we do not need to explicit its stochastic process at this stage. To deliver our result in the simplest possible form we focus on the case where the world stock of capital $K_{t}$ is predetermined but it can be allocated freely across countries within a period. ${ }^{1}$ The constraint on the allocation of capital is therefore given by

$$
K_{t} \geqslant \pi K_{A, t}+(1-\pi) K_{B, t}
$$

There is one representative agent in each of the two-country, with the same concave period utility $U\left(C_{J, t}, 1-H_{J, t}\right)$. Preferences are given by:

$$
U(C, 1-H)=\frac{C^{1-\sigma}}{1-\sigma} \times v(1-H)
$$

with $\sigma>0$ and $\sigma \neq 1$, or

$$
U(C, 1-H)=\log C+v(1-H) .
$$

Appendix A states the conditions on $v$ under which $U$ is a concave function and shows that under these conditions consumption and leisure are normal goods. The inter-temporal utility is the discounted sum of period utilities, with discount factor $\beta$.

\footnotetext{
1 This assumption will be removed in the quantitative exercise.
} 
Goods are perfectly mobile across countries. Markets are complete and competitive, so that the competitive equilibrium is Pareto optimal. We can therefore characterize equilibrium allocations by solving a social planner problem. The social planner chooses $C_{J, t}, H_{J, t}, K_{J, t}$, for $J=A, B$, and $K_{t+1}$ in order to maximize

$$
E_{0} \sum_{t=0}^{+\infty} \beta^{t}\left[\pi U\left(C_{A, t}, 1-H_{A, t}\right)+(1-\pi) U\left(C_{B, t}, 1-H_{B, t}\right)\right]
$$

subject to, for all $t \geqslant 0$

$$
\begin{cases}K_{t+1} \leqslant(1-\delta) K_{t}+\pi\left(F\left(K_{A, t}, H_{A, t} ; \theta_{A, t}\right)-C_{A, t}\right)+(1-\pi)\left(F\left(K_{B, t}, H_{B, t} ; \theta_{B, t}\right)-C_{B, t}\right) & \left(\lambda_{t} \geqslant 0\right), \\ K_{t} \geqslant \pi K_{A, t}+(1-\pi) K_{B, t} & \left(v_{t} \geqslant 0\right)\end{cases}
$$

and for a given $K_{0}$.

$\lambda_{t}$ and $v_{t}$ are the Lagrange multipliers associated to the resource and capital constraints. The optimal allocations satisfy the following nine conditions:

$$
\begin{aligned}
& K_{t+1}=(1-\delta) K_{t}+\pi\left[F\left(K_{A, t}, H_{A, t} ; \theta_{A, t}\right)-C_{A, t}\right]+(1-\pi)\left[F\left(K_{B, t}, H_{B, t} ; \theta_{B, t}\right)-C_{B, t}\right], \\
& K_{t}=\pi K_{A, t}+(1-\pi) K_{B, t}, \\
& \lambda_{t}=E_{t}\left[(1-\delta) \lambda_{t+1}+v_{t+1}\right],
\end{aligned}
$$

and, for $J=A, B$ :

$$
\begin{aligned}
& U_{1}\left(C_{J, t}, 1-H_{J, t}\right)=\lambda_{t}, \\
& \frac{U_{2}\left(C_{J, t}, 1-H_{J, t}\right)}{F_{2}\left(K_{J, t}, H_{J, t} ; \theta_{J, t}\right)}=\lambda_{t}, \\
& F_{1}\left(K_{J, t}, H_{J, t} ; \theta_{J, t}\right)=\frac{v_{t}}{\lambda_{t}}
\end{aligned}
$$

plus a transversality condition.

Finally, we define a news shock in country $J$ as the announcement in period 0 that the technology index $\theta_{J}$ will change at date $T$. In other words, $E_{0}\left(\theta_{J, t}\right)=E_{0}\left(\theta_{J, 0}\right) \forall 0 \leqslant t<T$ while $E_{0}\left(\theta_{J, t}\right) \neq E_{0}\left(\theta_{J, 0}\right) \forall t \geqslant T$. T is referred to as the realization date, periods 0 to $T-1$ are referred to as interim periods.

\subsubsection{A closed economy analog}

Before we proceed to the analysis of the two-country equilibrium allocation, let us define its closed economy analog, and put standard restrictions on it. The equilibrium allocations of this economy will happen to be a useful benchmark later on. The autarkic competitive equilibrium is the solution of the following social planner problem (variables with a superscript $c$ denote closed economy variables):

$$
\max E_{0} \sum_{t=0}^{+\infty} \beta^{t} U\left(C_{t}^{c}, 1-H_{t}^{c}\right)
$$

subject to, for all $t \geqslant 0$

$$
\begin{cases}K_{t+1}^{c} \leqslant(1-\delta) K_{t}^{c}+F\left(\mathcal{K}_{t}^{c}, H_{t}^{c} ; \theta_{t}^{c}\right)-C_{t}^{c} & \left(\lambda_{t}^{c}\right) \\ K_{t}^{c} \geqslant \mathcal{K}_{t}^{c} & \left(v_{t}^{c}\right)\end{cases}
$$

and $K_{0}^{c}$ given, where $\mathcal{K}_{t}^{c}$ denotes capital services used in the production process. ${ }^{2}$ The constraints and first-order conditions of the single country program are

$$
\begin{aligned}
& K_{t+1}^{c}=(1-\delta) K_{t}^{c}+F\left(\mathcal{K}_{t}^{c}, H_{t}^{c} ; \theta_{t}^{c}\right)-C_{t}^{c}, \\
& K_{t}^{c}=\mathcal{K}_{t}^{c}, \\
& \lambda_{t}^{c}=E_{t}\left[\lambda_{t+1}^{c}(1-\delta)+v_{t+1}^{c}\right], \\
& U_{1}\left(C_{t}^{c}, 1-H_{t}^{c}\right)=\lambda_{t}^{c}, \\
& \frac{U_{2}\left(C_{t}^{c}, 1-H_{t}^{c}\right)}{F_{2}\left(\mathcal{K}_{t}^{c}, H_{t}^{c} ; \theta_{t}^{c}\right)}=\lambda_{t}^{c}, \\
& F_{1}\left(\mathcal{K}_{t}^{c}, H_{t}^{c} ; \theta_{t}^{c}\right)=\frac{\nu_{t}^{c}}{\lambda_{t}^{c}}
\end{aligned}
$$

\footnotetext{
${ }^{2} \mathcal{K}_{t}^{c}$ can differ from the stock of physical capital available per capita $K_{t}$. This variable is useful to introduce the multiplier $v_{t}^{c}$.
} 
plus a transversality condition. Eqs. (7) to (12), which jointly define the autarkic allocation, are equivalent to (1) to (6) when $\pi=1$ or $\pi=0$. We make the following assumption.

Assumption (A). In the closed economy setup (7) to (12), preferences and technology are such that an equilibrium allocation exists and is unique.

\subsubsection{Synchronization and impossibility of business cycle fluctuations}

Turning back to the multi-country model, the following proposition states that news shocks are a powerful source of cross-country co-movements.

Proposition 1 (Synchronization - one-sector economies). For our one-sector multi-country model subjected to news shocks on $\theta_{A}$ or $\theta_{B}$, the equilibrium allocations are symmetric during the interim periods - i.e. from 0 to $T-1$.

(Intuitive) Proof of Proposition 1. We present here the main intuition behind the proof, leaving the formal proof of the existence and uniqueness of the symmetric solution during the interim periods for Appendix B.

To prove the proposition, we need to characterize allocations during the interim periods, from the announcement of the shock (period 0 ) to the period before its realization (period $T-1$ ). During those periods, all exogenous variable are constant, and we assume that they are symmetric across countries. Define a temporary equilibrium as the hyperplane defined by Eqs. (1) to (2) and, for both countries, (4) to (6). Those equations put restrictions on the endogenous variables for given expectations as defined in (3). Studying the properties of the temporary equilibrium hyperplane is enough to prove our result, and we will therefore not solve for expectations in (3). In other words, our result holds for any expectations, although we will restrict to rational expectations in the quantitative exercise.

Consider period 0 (the period of the news). The shock materializes in the right-hand side of Eq. (3), by a change in expectations that will pin down $\lambda_{0}$ (the left-hand side of (3)). Eqs. (1) and (2) and, for both countries, (4) to (6) are not affected by the shock. The economy in period 0 has to satisfy these equations. Note now that for a given country $J$, Eqs. (4) to (6) relate $\left(C_{J, 0}, H_{J, 0}, K_{J, 0}\right)$ to two multipliers $\left(\lambda_{0}, v_{0}\right)$ which are not country-specific and relate to exogenous variables $\left(\theta_{J, 0}\right)$ which are equal across country during the entire interim periods. Therefore, Eqs. (4) to (6) can be solved for $\left(C_{J, 0}, H_{J, 0}, K_{J, 0}\right)$ and the solution does not depends on $J$, meaning that the allocations are symmetric. This step requires that Eqs. (4) to (6) can uniquely be solved for $\left(C_{J, t}, H_{J, t}, K_{J, t}\right)$, which is what Assumption (A) guarantees. Finally, Eqs. (1) to (2) can be solved to obtain the multiplier $v_{0}$ and the capital level $K_{1}$. The same line of reasoning can be repeated for all dates between 0 and $T-1$. In period $T$, technology changes in one of the two countries $\left(\theta_{A, T} \neq \theta_{B, T}\right)$ and inputs get reallocated to the most productive economy, restoring the equality in marginal productivity of capital.

The synchronization result implies that consumptions in both countries react in exactly the same way to changes in expectations, as do labor inputs, capital inputs, outputs and savings. ${ }^{3}$ A shock expected to take place in only one of the two economies drives these economies perfectly symmetrically until the realization of the shock, at date $T$. Once the shock to $\theta$ gets realized, conditions (4) to (6) may (and usually do) drive these variables apart.

Note that this result does not depend on the nature of the shock: fiscal or preference news shocks would also imply perfect symmetry. Remark as well that synchronization occurs in the interim periods with country-specific news shocks as with common news shocks. If the underlying change in fundamental (here, $\theta_{A}$ or $\theta_{B}$ ) is permanent, our result holds regardless of the joint asymptotic properties, such as the presence or absence of cointegration between $\theta_{A}$ or $\theta_{B}$.

Synchronization in response to news is a cross-country feature. We are however also interested in within country comovements: do the news shocks create a domestic business cycle? The answer is no, as stated in the following proposition.

Proposition 2 (Domestic business cycles - one-sector economies). For our multi-country model subjected to a news shocks on $\theta_{A}$ or $\theta_{B}$ announced in period 0 for period $T$, during the interim periods equilibrium allocations display strictly negative correlation between consumption on the one side and investment and worked hours on the other side.

To prove this proposition, the following lemma and proposition are helpful.

Lemma 1 (Symmetry/autarky equivalence). If $\theta_{A, t}=\theta_{B, t}=\theta_{t}^{c} \forall t \in[0, T[$, equilibrium quantities of any one of the two countries of the multi-country model coincide with an equilibrium allocation of the closed economy model from 0 to $T$. Formally, for any variable $X$, $X_{A, t}=X_{B, t}=X_{t}^{c} \forall t \in[0, T[$.

\footnotetext{
${ }^{3}$ Domestic investments cannot be defined in this setup where only the world stock of capital matters. When capital location is predetermined, variables listed in the main text remain synchronized from 0 to $T-1$ but domestic investments differ in $T-1$ to achieve different levels of capital per capita in period $T$.
} 
Proof. When an equilibrium allocation of the two-country model is symmetric, i.e. $K_{A, t}=K_{B, t}, H_{A, t}=H_{B, t}$ and $C_{A, t}=C_{B, t}$, Eqs. (1) to (6) imply (7) to (12). Reciprocally, the duplication of an autarkic equilibrium allocation is an allocation of the two-country model.

Proposition 3 (Domestic business cycles - one-sector closed economy). Consider equilibrium allocations of a one-sector closed economy after news shocks on $\theta^{c}$ announced in period 0 for period $T$. During the interim periods, those allocations display negative correlation between consumption on the one side and investment and worked hours on the other side.

Proof. (This proposition is also proved in Beaudry and Portier, 2007.) Combining (7), (8), (10) and (12), we find that the temporary equilibrium of the closed economy is characterized by the following equations:

$$
\begin{aligned}
& F_{2}\left(K_{t}^{c}, H_{t}^{c} ; \theta_{t}^{c}\right) U_{1}\left(C_{t}^{c}, 1-H_{t}^{c}\right)=U_{2}\left(C_{t}^{c}, 1-H_{t}^{c}\right), \\
& I_{t}^{c}+C_{t}^{c}=F\left(K_{t}^{c}, H_{t}^{c} ; \theta_{t}^{c}\right)
\end{aligned}
$$

with $I_{t}^{c}=K_{t+1}^{c}-(1-\delta) K_{t}^{c}$. Total differentiation of (13) and (14) gives (dropping the arguments of the $U$ and $F$ functions):

$$
\begin{aligned}
& U_{12} d C^{c}-U_{22} d H^{c}=F_{2}\left(U_{11} d C^{c}-U_{12} d H^{c}\right)+U_{1} F_{22} d H^{c}, \\
& d C^{c}=F_{2} d H^{c}+G_{3} d I^{c} .
\end{aligned}
$$

The first equation rewrites:

$$
\left(-U_{22}+F_{2} U_{12}-F_{22} U_{1}\right) d H^{c}=-\left(U_{12}-F_{2} U_{11}\right) d C^{c},
$$

or equivalently

$$
-a_{1} d H^{c}=a_{2} d C^{c}
$$

with $a_{1}=\left(-U_{22}+F_{2} U_{12}-F_{22} U_{1}\right)$ and $a_{2}=U_{12}-F_{2} U_{11}$. Let us show that $a_{1}>0$. We use Eq. (13) to substitute $F_{2}$ away:

$$
\begin{aligned}
a_{1}>0 & \Longleftrightarrow \quad-U_{22}+F_{2} U_{12}-F_{22} U_{1}>0 \\
& \Longleftrightarrow U_{12}>\frac{1}{F_{2}}\left(U_{22}+F_{22} U_{1}\right) \\
& \Longleftrightarrow U_{12}>\frac{U_{1}}{U_{2}}\left(U_{22}+F_{22} U_{1}\right) \\
& \Longleftrightarrow U_{12}>\frac{U_{22} U_{1}}{U_{2}}+\frac{F_{22} U_{1}}{F_{2}} .
\end{aligned}
$$

As $\frac{F_{22} U_{1}}{F_{2}}<0$, this inequality holds when (A.3) or (A.5) hold (condition for normality). One can therefore write

$$
d H^{c}=-\frac{a_{2}}{a_{1}} d C^{c} .
$$

Using this equation and plugging it in the resource constraint (16) gives:

$$
\left(1+F_{2} \frac{a_{2}}{a_{1}}\right) d C^{c}=-d I^{c} .
$$

Let us show $a_{2}>0$.

$$
\begin{aligned}
a_{2}>0 & \Longleftrightarrow U_{12}>F_{2} U_{11} \\
& \Longleftrightarrow U_{12}>\frac{U_{11} U_{2}}{U_{1}} .
\end{aligned}
$$

This last inequality is actually one of the condition for normality (A.6), that we have shown to hold for balanced growth compatible preferences (see Appendix A). We have then proved that $a_{1}>0$ and $a_{2}>0$. Therefore, $\left(1+F_{2} a_{1} a_{2}\right)>0$, so that, according to (19), $d C^{c} / d I^{c}<0$. Similarly, (18) implies $d H^{c} / d C^{c}>0$. When investment increases, consumption strictly decreases while hours (and therefore output) strictly decrease. Business cycles movements are not possible following a news shock.

Proof of Proposition 2. The proposition is directly implied by Proposition 3 and by Lemma 1.

We now modify our setup to a two-sector economy in order to show that the synchronization result remains valid and that business cycles co-movements are possible, meaning that consumption and investment (or hours) do not exhibit negative co-movement. 


\subsection{A two-sector two-country model}

\subsubsection{The setup}

Now we consider a two-country two-sector model. The production of the consumption good in country $J$ requires capital, $K_{J, t}^{c}$, and labor, $H_{J, t}^{c}$. The production function $F^{c}\left(K_{J, t}^{c}, H_{J, t}^{c} ; \theta_{J, t}^{c}\right)$ is assumed to be concave and $\theta_{J, t}^{c}$ denotes the country-specific technology index in the consumption sector. Similarly, an homogeneous investment good is produced using capital and labor with a concave production function common to both countries, $F^{x}\left(K_{J, t}^{x}, H_{J, t}^{x} ; \theta_{J, t}^{x}\right)$ for $J=A, B$ with $\theta_{J, t}^{x}$ the technology index in the investment sector.

Mobility of capital is assumed to frictionless across both countries and sectors. Feasible allocations of capital must satisfy $K_{t} \geqslant \pi\left(K_{A, t}^{c}+K_{A, t}^{x}\right)+(1-\pi)\left(K_{B, t}^{c}+K_{B, t}^{x}\right)$.

Consumption per capita is bounded above by the total production of the consumption good, while world investment is bounded above by the total production of the investment good. Denoting by $X_{J}$ the investment in country $J$, the law of motion of aggregate capital is

$$
K_{t+1} \leqslant(1-\delta) K_{t}+\pi X_{A, t}+(1-\pi) X_{B, t} .
$$

The equilibrium outcomes can again be derived by solving a social planner's problem where the variables $C_{J, t}, X_{J, t}, H_{J, t}^{c}$, $H_{J, t}^{x}, K_{J, t}^{c}, K_{J, t+1}^{x}$, for $J=A, B$, and $K_{t+1}$ are chosen in order to

$$
\max E_{0} \sum_{t=0}^{+\infty} \beta^{t}\left[\pi U\left(C_{A, t}, 1-H_{A, t}\right)+(1-\pi) U\left(C_{B, t}, 1-H_{B, t}\right)\right]
$$

subject to, for all $t \geqslant 0$

$$
\left\{\begin{array}{l}
\pi C_{A, t}+(1-\pi) C_{B, t} \leqslant \pi F^{c}\left(K_{A, t}^{c}, H_{A, t}^{c} ; \theta_{A, t}^{c}\right)+(1-\pi) F^{c}\left(K_{B, t}^{c}, H_{B, t}^{c} ; \theta_{B, t}^{c}\right), \\
\pi X_{A, t}+(1-\pi) X_{B, t} \leqslant \pi F^{x}\left(K_{A, t}^{x}, H_{A, t}^{x} ; \theta_{A, t}^{x}\right)+(1-\pi) F^{x}\left(K_{B, t}^{x}, H_{B, t}^{x} ; \theta_{B, t}^{X}\right), \\
K_{t} \geqslant \pi\left(K_{A, t}^{c}+K_{A, t}^{x}\right)+(1-\pi)\left(K_{B, t}^{c}+K_{B, t}^{x}\right), \\
H_{A, t} \geqslant H_{A, t}^{x}+H_{A, t}^{c} \\
H_{B, t} \geqslant H_{B, t}^{x}+H_{B, t}^{c} \\
K_{t+1} \leqslant(1-\delta) K_{t}+\pi X_{A, t}+(1-\pi) X_{B, t}
\end{array}\right.
$$

and $K_{0}$ given.

Similarly to the one-sector case, we also consider the closed economy analog to the two-country two-sector model. We make Assumption $\left(A^{\prime}\right)$, which is the counterpart in this two-sector setup of $(A)$ in the one-sector case.

Assumption $\left(\mathbf{A}^{\prime}\right)$. Preference and technology are such that in a closed economy setup, an equilibrium allocation exists and is unique.

\subsubsection{Synchronization and possibility of business cycle fluctuations}

In the setup outlined in the preceding paragraph, we have the following result:

Proposition 4 (Synchronization - two-sector economies). When our two-country two-sector model is subjected to a news shocks on $\theta_{A}^{c}, \theta_{A}^{X}, \theta_{B}^{c}$ or $\theta_{B}^{X}$ announced in period 0 for period $T$, then the equilibrium allocations are symmetric during the interim periods - i.e. from 0 to $T-1$.

(Intuitive) Proof of Proposition 4. Once again, we only present here the intuition of the proof of this result. The formal proof of the existence and uniqueness of the symmetric solution during the interim periods is a straightforward replication of the one-sector case (Appendix B) with the help of the multi-sectoral production function $G$ defined below.

We define $G\left(K_{J, t}, H_{J, t}, X_{J, t} ; \theta_{J, t}\right)=C_{J, t}$ as the value function of the static problem:

$$
\max C_{J, t}
$$

subject to

$$
\left\{\begin{array}{l}
C_{J, t} \leqslant F^{c}\left(K_{J, t}^{c}, H_{J, t}^{c} ; \theta_{J, t}^{c}\right), \\
X_{J, t} \leqslant F^{x}\left(K_{J, t}^{x}, H_{J, t}^{x} ; \theta_{J, t}^{x}\right), \\
K_{J, t} \geqslant K_{J, t}^{x}+K_{J, t}^{c}, \\
H_{J, t} \geqslant H_{J, t}^{x}+H_{J, t}^{c}
\end{array}\right.
$$

with the notation $\theta_{J, t}=\left(\theta_{J, t}^{c}, \theta_{J, t}^{x}\right)$. The interpretation of function $G$ is the maximum level of consumption per capita achievable when investing $X_{J, t}$, using inputs $K_{J, t}$ and $H_{J, t}$ (and allocating them optimally across sectors) given technology $\theta_{J, t}$. It is easy to show that when the two production functions $F^{c}$ and $F^{x}$ are both Cobb-Douglas with the same 
coefficient, i.e. when the model boils down to a one-sector model, function $G$ is of the form $G\left(K_{J, t}, H_{J, t}, X_{J, t} ; \theta_{J, t}\right)=$ $F\left(K_{J, t}, H_{J, t} ; \theta_{J, t}\right)-X_{J, t}$.

With this definition, the social planner problem becomes very similar to the problem of the one-sector model. ${ }^{4}$ It writes

$$
\max E_{0} \sum_{t=0}^{+\infty} \beta^{t}\left[\pi U\left(C_{A, t}, 1-H_{A, t}\right)+(1-\pi) U\left(C_{B, t}, 1-H_{B, t}\right)\right]
$$

subject to for all $t \geqslant 0$

$$
\begin{cases}\pi C_{A, t}+(1-\pi) C_{B, t} \leqslant \pi G\left(K_{A, t}, H_{A, t}, X_{A, t} ; \theta_{A, t}\right)+(1-\pi) G\left(K_{B, t}, H_{B, t}, X_{B, t} ; \theta_{B, t}\right) & \left(\lambda_{t} \geqslant 0\right), \\ K_{t+1} \leqslant(1-\delta) K_{t}+\pi X_{A, t}+(1-\pi) X_{B, t} & \left(\mu_{t} \geqslant 0\right), \\ K_{t} \geqslant \pi K_{A, t}+(1-\pi) K_{B, t} & \left(v_{t} \geqslant 0\right)\end{cases}
$$

and $K_{0}$ given, with $\lambda_{t}, \mu_{t}$ and $v_{t}$ the Lagrange multipliers. The optimal allocations satisfy the following twelve constraints

$$
\begin{aligned}
& \pi C_{A, t}+(1-\pi) C_{B, t}=\pi G\left(K_{A, t}, H_{A, t}, X_{A, t} ; \theta_{A, t}\right)+(1-\pi) G\left(K_{B, t}, H_{B, t}, X_{B, t} ; \theta_{B, t}\right), \\
& K_{t+1} \leqslant(1-\delta) K_{t}+\pi X_{A, t}+(1-\pi) X_{B, t}, \\
& K_{t} \geqslant \pi K_{A, t}+(1-\pi) K_{B, t}, \\
& \mu_{t}=E_{t}\left[(1-\delta) \mu_{t+1}+v_{t+1}\right]
\end{aligned}
$$

and for $J=A, B$

$$
\begin{aligned}
& U_{1}\left(C_{J, t}, 1-H_{J, t}\right)=\lambda_{t}, \\
& \frac{U_{2}\left(C_{J, t}, 1-H_{J, t}\right)}{G_{2}\left(K_{J, t}, H_{J, t}, X_{J, t} ; \theta_{J, t}\right)}=\lambda_{t}, \\
& -G_{3}\left(K_{J, t}, H_{J, t}, X_{J, t} ; \theta_{J, t}\right)=\frac{\mu_{t}}{\lambda_{t}}, \\
& G_{1}\left(K_{J, t}, H_{J, t}, X_{J, t} ; \theta_{J, t}\right)=\frac{\nu_{t}}{\lambda_{t}}
\end{aligned}
$$

plus a transversality condition.

As in the one-sector model, the temporary equilibrium is in each period $t$ belongs to the hyperplane defined by Eqs. (20) to (22) and, for both country, (24) to (27). We consider period 0. Expectations are taken as given from (23), which pins down $\mu_{0}$. Eqs. (24) to (27) relate allocations $\left(C_{J, 0}, H_{J, 0}, X_{J, 0}, K_{J, 0}\right)$ to three multipliers $\left(\lambda_{0}, \mu_{0}, v_{0}\right)$ which are not country specific and relate to the exogenous variables $\left(\theta_{J, 0}\right)$ which are equal across country in period 0 (and all along until $T-1$ ). Under Assumption ( $\left.\mathrm{A}^{\prime}\right)$, Eqs. (24) to (27) can be solved for $\left(C_{J, 0}, H_{J, 0}, X_{J, 0}, K_{J, 0}\right)$ as functions of $\left(\lambda_{0}, \mu_{0}, v_{0}\right)$, and the solution does not depends on $J$. Then Eqs. (20) to (22) can be solved to obtain $\lambda_{0}, v_{0}$ and $K_{1}$. Allocations in 0 are therefore symmetric. The reasoning can be applied to periods 1 to $T-1 .^{5}$ In period $T$, the news shock is realized and conditions (24) to (27) no longer impose symmetry. Note that once again, during the interim periods, synchronization of allocations in $A$ and $B$ holds regardless of the nature of the news.

Although the symmetry result obtained in the one-sector economy still holds in a two-sector setup, the impossibility of business cycles fluctuations no longer strictly holds in two-sector models. As allocations are symmetrical during the interim periods, the two-sector two-country economy inherits the properties of the closed economy analogue. We can therefore use the result in Beaudry and Portier (2007) that shows that consumption, investment and worked hours cannot be all strictly increasing, but that weak business cycle movements are possible, meaning that consumption does not decrease on impact while investment and hours increase on impact. This result is stated in the following proposition.

Proposition 5 (Domestic business cycles - two-country two-sector economy). Consider equilibrium allocations of a two-country twosector economy after news shocks announced in period 0 for period T. During the interim periods, consumption, investment and worked hours cannot be all strictly increasing in all periods of the interim phase. Nevertheless, weak business cycle movements are possible, meaning that consumption, investment and hours worked can all weakly increase during the interim phase.

Proof. As in the one-sector case, this proposition is implied by Proposition 6 below (also proven in Beaudry and Portier, 2007) and by a lemma similar to Lemma 1 that we state below.

\footnotetext{
4 For that reason, an extension to an $n$-sector model, $n>2$, is straightforward.

5 Note that this proof works when the Hessian of the function $G$ has non-zero elements, so that Eqs. (24) to (27) can always be solved for $\left(C_{J, t}, H_{J, t}, X_{J, t}, K_{J, t}\right)$. In the one-sector case, $G_{3}=-1$ and the system (24) to (27) is singular. Proposition 4 still holds but the proof has to follow the one of Proposition 1.
} 
Lemma 2 (Symmetry/autarky equivalence in the two-sector model). If all exogenous variables are symmetric across countries $\forall t \in[0, T$, equilibrium quantities of any one of the two countries of the multi-country model coincide with an equilibrium allocation of the closed economy model from 0 to $T$. Formally, for any variable $X, X_{A, t}=X_{B, t}=X_{t}^{c} \forall t \in[0, T[$.

Proof. The proof of Lemma 2 is similar to the one of Lemma 1.

Proposition 6 (Domestic business cycles - two-sector closed economy). Consider equilibrium allocations of a two-sector closed economy after news shocks announced in period 0 for period $T$. During the interim periods, consumption, investment and worked hours cannot be all strictly increasing. Nevertheless, weak business cycle movements are possible, meaning consumption, investment and hours works can all weakly increase during the interim phase.

Proof. To prove this proposition, it is helpful to work with the dual form of the temporary equilibrium. Let $\Omega^{C}\left(w_{t}, r_{t}, C_{t}\right)$ represent the unit cost function for the consumption-good sector (where $r$ is the rental rate of capital and $w$ in the wage rate) and let $\Omega^{I}\left(w_{t}, r_{t}, I_{t}\right)$ represent the unit cost function for the investment-good sector. Having assumed that production functions are concave, both unit cost functions are convex and increasing in their three arguments. Note that if we restrict to constant returns to scale function, $C$ and $I$ are not arguments of the functions $\Omega$. A temporary equilibrium, with the consumption good being the numéraire and with $q$ being the price of investment, must then satisfy the following set of five conditions:

$$
\begin{aligned}
& \Omega^{C}\left(w_{t}, r_{t}, C_{t}\right)=1, \\
& \Omega^{I}\left(w_{t}, r_{t}, I_{t}\right)=q_{t}, \\
& \Omega_{w}^{C}\left(w_{t}, r_{t}, C_{t}\right) C_{t}+\Omega_{w}^{I}\left(w_{t}, r_{t}, I_{t}\right) I_{t}=H_{t}, \\
& \Omega_{r}^{C}\left(w_{t}, r_{t}, C_{t}\right) C_{t}+\Omega_{r}^{I}\left(w_{t}, r_{t}, I_{t}\right) I_{t}=K_{t}, \\
& U_{2}\left(C_{t}, 1-H_{t}\right)=w_{t} U_{1}\left(C_{t}, 1-H_{t}\right) .
\end{aligned}
$$

Note that $K_{t}$ being predetermined, this system implicitly defines a set of values for $C_{t}, I_{t}$ and $H_{t}$ (as well as values for $r_{t}$, $w_{t}$ and $\left.q_{t}\right)$.

To prove our result by contradiction, assume that $C_{t}, I_{t}$ and $H_{t}$ all strictly increase after the news shock, then Eq. (32) implies (by normality of leisure and consumption) that $w_{t}$ increases. If $w_{t}$ and $C_{t}$ increase, Eq. (28) implies that $r_{t}$ decreases. It is then impossible to satisfy Eq. (31) given that concavity of the production function implies that $\Omega_{r, r}^{C}<0, \Omega_{r, w}^{C}>0$, $\Omega_{r, C}^{C}>0, \Omega_{r, r}^{I}<0, \Omega_{r, w}^{I}>0$ and $\Omega_{r, C}^{I}>0$.

Let us now give an example of a model in which weak business cycles can be observed following a news shock. Assume that the consumption production function is any concave function and that investment is produced only with labor. ${ }^{6}$ Also assume that preferences are quasi-linear: $U\left(C_{t}, 1-H_{t}\right)=\log C_{t}+B\left(1-H_{t}\right)$. In that case, the temporary equilibrium is given by:

$$
\begin{aligned}
& \Omega^{C}\left(w_{t}, r_{t}, C_{t}\right)=1, \\
& \Omega^{I}\left(w_{t}, I_{t}\right)=q_{t}, \\
& \Omega_{w}^{C}\left(w_{t}, r_{t}, C_{t}\right) C_{t}+\Omega_{w}^{I}\left(w_{t}, I_{t}\right) I_{t}=H_{t}, \\
& \Omega_{r}^{C}\left(w_{t}, r_{t}, C_{t}\right) C_{t}=K_{t}, \\
& B=\frac{w_{t}}{C_{t}} .
\end{aligned}
$$

Consider the period $t=0$ in which the news occurs. Assume again an increase in $I_{0}$. If $d C_{0}>0$, (37) implies that $d w_{0}>0$. Then (33) implies $d r_{0}<0$. Then $\Omega_{r}^{C}$ increases and given that $d C_{0}>0$, (36) is violated. If $d C_{0}<0$, (37) implies that $d w_{0}<0$. Then (33) implies $d r_{0}>0$. Then $\Omega_{r}^{C}$ decreases and given that $d C_{0}<0$, (36) is violated. If $d C_{0}=0$, (37) implies that $d w_{0}=0$. (33) implies that $d q_{0}>0$. (36) is not violated and (35) implies $d H_{0}>0$. On impact, the news increases investment, hours and keeps consumption constant. The price of capital $q$ will increase if returns to scale are decreasing in the production of the investment good, and will stay constant if returns to scale are constant.

Note that if $d I_{1}>0$, the same analysis can be repeated in period 1. Capital being above the pre-news level, consumption also needs to increase to satisfy (36), and the three variables increase during the rest of the interim periods (such a dynamics is indeed what we obtain in the quantitative analysis that follows, which is based on an extended version of the example presented above).

\footnotetext{
${ }^{6}$ A less drastic assumption would be that capital is fixed or quasi-fixed in that sector. Results would be the same in such a model.
} 
We have shown in this section that local news shocks synchronize economies, that they fail to create domestic business cycle fluctuations in one-sector models, but that an increase in investment, hours and consumption (weakly for consumption in the fist period) is possible in some specific two-sector models. In the next section, we propose a quantitative two-country two-sector model in which local news shocks do create a domestic business cycle that is transmitted abroad. We contrast the quantitative responses that we obtain with those of more standard Backus et al. (1994)-type models.

\section{The international transmission of news shock in a two-country two-sector model}

As established in the previous section, a domestic productivity news shock may act as a synchronizing force in international business cycles. Nevertheless, allocations may display counter-factual movements for two reasons.

First, news shocks tend to move consumption on the one hand and investment and hours on the other hand in opposite directions during the interim periods (from 0 to $T-1$ ) - as we have shown, this is actually what happens in a onesector model. Following a good news about future technology in country $A$, the representative agent of both economies is wealthier, as one of the asset in her portfolio (capital located in $A$ ) will serve higher return in the future. The two representative agents therefore consume more of all normal goods, typically consumption and leisure. As technology has not yet improved, productivity of labor is not higher, and therefore no substitution effect pushes labor supply upwards. As a result, worked hours fall and consumption rises in both countries. The only way to finance this consumption boom is therefore a drop in investment in both countries. Things are different in the specific two-sector model we have introduced in the previous section, which combines infinitely elastic labor supply and the absence of capital in the investment sector. In this model, the increase in consumption is met by an increase in employment, not a decrease in investment. This arises because current consumption decisions are essentially decoupled from current investment decisions, as it can be seen from Eqs. (33) to (37). In other words, agents in the economy can determine how much investment to undertake without this decision having a direct feedback on how much the economy can currently consume.

Second, when the local technological improvement occurs (in period $T$ ), it is well known that models have trouble in reproducing the cross-country correlation of inputs (the so-called "quantity anomaly"). There are strong incentives to use productive inputs more intensively in the country benefiting from a positive productivity differential. This leads to negative cross-correlations of output, investment and labor input. In the quantitative model, we will assume that technological improvements follow a slow diffusion process, which will mitigate the quantity anomaly.

In this section, we first propose a two-country version of a model introduced by Beaudry and Portier (2004). We show that the model is able to generate international co-movements and domestic business cycle following a news shock. We then show that quantitative versions of one- or two-sector BKK-like models fail generating such a response of the economy to a news shock.

\subsection{The proposed two-country two-sector model}

We will present the structure of the model in different steps. We first elaborate on the closed economy example of the precedent section, which could exhibit comovements between consumption, investment and hours. In a second step, we discuss which features of the model help generate expansions, as opposed to recessions, once the economy receives a positive news about future productivity. The third and final building block of the model characterizes the international trade structure.

We start with a two-sector economy. The distinction between the consumption good and the investment good is crucial, because it prevents agents to achieve higher levels of consumption as soon as they receive the news by simply eating their capital. As in the example above, we add Hansen-Rogerson quasi-linear preferences and assume that capital is a fixed input for the production of the investment good. The important element here is that the reallocation of inputs between the consumption- and investment-good sector is costly, so that increasing consumption in the interim periods cannot be done easily by shifting resources away from the investment-good sector (a less extreme assumption would be to introduce adjustment cost of capital reallocation but this would further increase the model dimension). We have shown earlier that the temporary equilibrium of a model which combines together these ingredients can display weak business cycles following a news shock, meaning that consumption, investment and hours do not move in opposite directions.

We make some further assumptions to make sure that a good news creates a boom, not a recession. This second set of assumptions is related to the properties of the intertemporal equilibrium. First, we assume some complementarity between capital and labor in the consumption-good sector. This implies that capital accumulation is needed to take advantage of a good news in the interim periods by increasing consumption. Capital-labor complementarity creates an incentive to increase both investment and consumption. Second, there are decreasing returns in the variable factor (labor) in the investment good sector. This prevents a surge in investment in the last period before the realization of the productivity improvements. Third, productivity improvements take place in the consumption-good sector, not in the investment-good one. News in the investment sector would reduce the value of current physical capital. Therefore, they would provide an incentive to undertake investment after the interim periods.

Our last building block describes the international aspects of this economy. We impose static gains to trade to make sure that goods are traded internationally in steady-state. Each final good is produced as a bundle of intermediate goods from 
both countries. In other words, final consumption and investment are defined as CES aggregators of home and foreign intermediate goods. Hence, four intermediate goods exist, one consumption-oriented and one investment-oriented intermediate good in each country.

The specification of final goods bundles we retain does not need to give the same weight to home and foreign intermediate goods. The economy can (and does in our parametrization) exhibit home bias. It means that preferences differ across the two countries, and implies that the propositions of the previous section no longer strictly hold. ${ }^{7}$ In the extreme case where consumers only consume and invest domestically produced intermediate goods, the two countries never trade and their equilibrium allocations become unrelated.

\subsubsection{The setup}

The building blocks discussed above allow us to generate news-driven international co-movements. We now expose in more details the structure of the economy and introduce the notations. We consider a stylized economy composed of two countries, $A$ and $B$, which are symmetric, with respective population $N_{A}$ and $N_{B}$.

2.1.1.1. Final goods There are two final goods: a consumption good and an investment one. The consumption good of country $A$ combines two intermediate goods, $Z_{A A}$ which is produced at home and $Z_{B A}$ which is imported from country $B{ }^{8}$ to produce the consumption good, according to the following constant returns CES aggregator:

$$
c_{A, t}=\left[b_{C} Z_{A A, t}^{\nu_{C}}+\left(1-b_{C}\right) Z_{B A, t}^{v_{C}}\right]^{\frac{1}{v_{C}}}, \quad 0<b_{C}<1 .
$$

The analogue consumption bundle for country $B$ is

$$
C_{B, t}=\left[\left(1-b_{C}\right) Z_{A B, t}^{\nu_{C}}+b_{C} Z_{B B, t}^{\nu_{C}}\right]^{\frac{1}{\nu_{C}}} \text {. }
$$

Similarly, the final investment good in country $A$ is produced by combining two intermediate goods, $X_{A A}$ which is produced at home and $X_{B A}$ which is imported from country $B$, according to

$$
I_{A, t}=\left[b_{I} X_{A A, t}^{v_{I}}+\left(1-b_{I}\right) X_{B A, t}^{v_{I}}\right]^{\frac{1}{v_{I}}}, \quad 0<b_{I}<1 .
$$

Investment in each country is then used to increment the domestic stock of capital:

$$
K_{A, t+1}=(1-\delta) K_{A, t}+I_{A, t}=(1-\delta) K_{A, t}+\left[b_{I} X_{A A, t}^{\nu_{I}}+\left(1-b_{I}\right) X_{B A, t}^{v_{I}}\right]^{\frac{1}{\nu_{I}}}
$$

and

$$
K_{B, t+1}=(1-\delta) K_{B, t}+I_{B, t}=(1-\delta) K_{B, t}+\left[\left(1-b_{I}\right) X_{B A, t}^{v_{I}}+b_{I} X_{B B, t}^{v_{I}}\right]^{\frac{1}{v_{I}}}
$$

2.1.1.2. Intermediate goods Country $A$ produces a consumption-oriented intermediate good $Z_{A}$ using capital and labor $H_{A}$ according to the following CES technology:

$$
Z_{A, t}=\left[a\left(\theta_{A, t} \bar{H}_{A, Z}^{1-\varphi} H_{A, t}^{\varphi}\right)^{v}+(1-a) K_{A, t}^{v}\right]^{\frac{1}{v}} .
$$

$\theta_{A, t}$ denotes the technology index which will serve as the exogenous driving force, $\bar{H}_{A, Z}$ represents some fixed labor required in the production of the consumption-oriented intermediate good. We will restrict attention to cases where the elasticity of substitution between $K$ and labor in the final goods sector is no greater that one. This intermediate good is then either used at home $\left(Z_{A A}\right)$ or exported $\left(Z_{A B}\right)$.

Country $A$ also produces a investment-oriented intermediate good $X_{A}$ using variable labor $\widetilde{H}_{A}$ according to the following technology:

$$
X_{A, t}=\widetilde{\theta}_{A, t} \bar{K}_{A}^{1-\alpha_{X}-\beta_{X}} \bar{H}_{A, X}^{\beta_{X}} \widetilde{H}_{A, t}^{\alpha_{X}} .
$$

$\widetilde{\theta}_{A, t}$ denotes the technology index in the investment-oriented intermediate good sector. We assume that some labor $\bar{H}_{A, X}$ and all the capital used in this sector $\bar{K}_{A}$ are in fixed quantity. As we explained, the absence of possibility of reallocating capital between the two sectors is crucial to obtain news-driven business cycles.

In country $B$, the analogue consumption-oriented and investment-oriented intermediate goods are given respectively by

$$
Z_{B, t}=\left[a\left(\theta_{B, t} \bar{H}_{B, Z}^{1-\varphi} H_{B, t}^{\varphi}\right)^{v}+K_{B, t}^{v}\right]^{\frac{1}{v}}
$$

and

$$
X_{B, t}=\widetilde{\theta}_{B, t} \bar{K}_{B}^{1-\alpha_{X}-\beta_{X}} \bar{H}_{B, X}^{\beta_{X}} \widetilde{H}_{B, t}^{\alpha_{X}}
$$

\footnotetext{
7 For instance, the closed economy analog we use to prove existence and uniqueness of the symmetric equilibrium is now a meaningless object.

8 We adopt here the following notation: $Z_{I J}$ means good $Z$ produced in $I$ and used in $J$.
} 
2.1.1.3. Preferences The representative household of country $A$ has preferences over individual consumption and hours worked at all periods, discounts period utility at rate $\beta$ and we assume that the period utility is of the Hansen-Rogerson type (referred to as case (b) in Appendix A):

$$
\mathcal{U}_{A}\left(c_{A, t}, h_{A, t}, \widetilde{h}_{A, t}\right)=\ln c_{A, t}-\chi\left(h_{A, t}+\widetilde{h}_{A, t}+\bar{h}_{A}\right) .
$$

The preferences of agents in country $B$ parallel those of country $A$.

\subsubsection{Equilibrium allocations}

The two welfare theorems apply in this setup and we solve for an optimal allocation. The Social Planner chooses $\left\{c_{J, t}, h_{J, t}, \widetilde{h}_{J, t}, I_{J, t}, K_{J, t+1}, Z_{I J}\right\}_{J=A, B}$ in order to

$$
\max E_{0} \sum_{t=0}^{+\infty} \beta^{t}\left[N_{A}\left(\ln c_{A, t}-\chi\left(h_{A, t}+\widetilde{h}_{A, t}+\bar{h}_{A}\right)\right)+N_{B}\left(\ln c_{B, t}-\chi\left(h_{B, t}+\widetilde{h}_{B, t}+\bar{h}_{B}\right)\right)\right]
$$

subject to conditions (38) to (45) and the following resource conditions

$$
\left\{\begin{array}{l}
C_{A, t}=N_{A} c_{A, t}, \\
C_{B, t}=N_{B} c_{B, t}, \\
H_{A, t}=N_{A} h_{A, t}, \\
H_{B, t}=N_{B} h_{B, t}, \\
\widetilde{H}_{A, t}=N_{A} \widetilde{h}_{A, t}, \\
\widetilde{H}_{B, t}=N_{B} h_{B, t}, \\
Z_{A, t} \geqslant Z_{A A, t}+Z_{A B, t}, \\
Z_{B, t} \geqslant Z_{B A, t}+Z_{B B, t}, \\
X_{A, t} \geqslant X_{A A, t}+X_{A B, t}, \\
X_{B, t} \geqslant X_{B A, t}+X_{B B, t}, \\
N_{A} \bar{h}_{A} \geqslant \bar{H}_{A, X}+\bar{H}_{A, Z}, \\
N_{B} \bar{h}_{B} \geqslant \bar{H}_{B, X}+\bar{H}_{B, Z,}, \\
K_{A, 0}=K_{B, 0} \text { given, }
\end{array}\right.
$$

where small letters denote per capita variables.

Once this social optimum problem solved, one can backup prices and National Income and Product Accounts. We choose the consumption good in country $A$ as the numéraire. For $I \in\{A, B\}, q_{I}$ will denote the price of the investment good, $p_{I}$ the price of the consumption good (with $p_{A}=1$ ) and $w_{I}$ the wage rate. We define nominal GDP of country $I$ as $p_{I} C_{I}+q_{I} I_{I}$. Period 0 , in which the economy is at the steady-state, is chosen as the base period. Using a subscript $S$ for steady-state values, real GDP in any period will be computed as $p_{I}^{S} C_{I}+q_{I}^{S} I_{I}$. Baskets of imports and of exports are computed in the same way, using period 0 as the base period for prices. Finally, Total Factor Productivity will be measured as if the model was a one-sector Cobb-Douglas economy

$$
\operatorname{TFP}_{I, t}=\frac{p_{I}^{S} C_{I}+q_{I}^{S} I_{I}}{K_{I, t}^{1-s h}\left(H_{I, t}+\widetilde{H}_{I, t}\right)^{s h}}
$$

where $s h$ is the steady-state labor income share.

Because the model has no analytical solution, we turn to numerical analysis.

\subsubsection{Parametrization}

We propose here a numerical analysis of the model allocations following a news shock on productivity in one country. The period is one quarter. We assume that the two countries have the same size, normalize productivity $\theta_{I}$ to 1 and set $\beta$ to 0.984 . Parameters $\widetilde{\theta}, a, \chi, b$ and $\delta$ are set to match the following steady-state values: consumption to GDP ratio is 0.7 , labor income is $2 / 3$ of GDP, imports and exports represent 25\% of GDP each and capital to annual GDP ratio is 1.25 .

For the elasticity of substitution between domestic and foreign intermediate goods, we choose a value of 0.4 , meaning that the two intermediate goods are complementary. This level of elasticity is at the bottom end of what is generally chosen in the literature but in line with Corsetti et al. (2008). As we do not allow for any common component in shocks, relatively strong complementarities are needed for local technological shocks to generate positive co-movements when implemented. On the contrary, complementarity is not needed for the response to news as during the interim periods: the two countries comove positively regardless of the degree of complementarity. Finally, capital and labor are assumed to be complementary in the production of the consumption-oriented intermediate goods, with elasticity 0.2. This elasticity is the one estimated by Beaudry and Portier (2004). $\alpha_{X}, \beta_{X}$ and $\phi$ are also taken from Beaudry and Portier (2004).

We study the response of the economy to a non-expected permanent technological shock in the consumption-oriented intermediate good sector of country $A, \theta_{A, t}$, maintaining other technological parameters constant. As identified in Beaudry and Portier (2006), we assume that technological improvements slowly diffuse. More specifically, $\theta_{A, t}$ follows: 

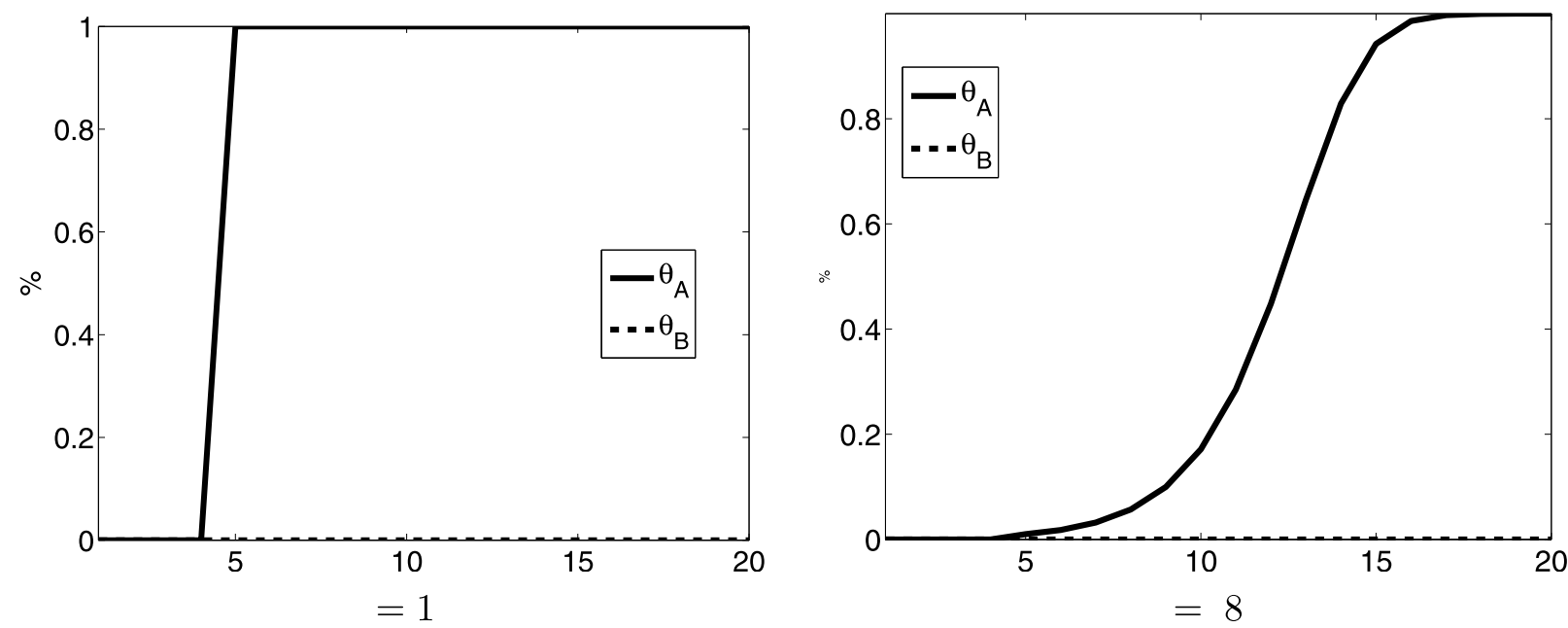

Fig. 1. Diffusion process, technological news in country $A$. In this figure, we display the time path of technology in the consumption-oriented intermediate good sector $\theta$ (left panel) in the two countries, expressed in percentage deviation from their steady-state level.

$$
\begin{aligned}
& \theta_{A, t}=1+\frac{u_{A, t}}{100}, \\
& u_{A, t}=u_{A, t-1}+\rho\left[u_{A, t-1} \times\left(1-u_{A, t-1}\right)\right]+\varepsilon_{A, t-T}
\end{aligned}
$$

with $0<\rho \leqslant 1$. The economy is supposed to be at steady-state before period 0 , with $u_{A, 0}=0$ and $\theta_{A, 0}=1$. The economy is hit in period 0 by a shock $\varepsilon_{A, 0}=1 \%$. The shock does not affect productivity for the first $T$ periods, although it is observed in period 0 by the agent. After implementation, $u_{t}$ slowly increases and asymptotically reaches 1 , so that $\theta_{A, t}$ permanently increases by $1 \%$. We assume $T=4$ and successively consider two diffusion speeds (see Fig. 1 ).

We first set $\rho$ to 1 , meaning that productivity jumps in period 5. This extreme case is helpful to distinguish what happens before and after the realization of the productivity improvement. We then impose $\rho=0.8$. In that case, diffusion takes approximately 12 quarters. Notice that 5 quarters after the beginning of the diffusion, $\theta_{A}$ is not larger than $0.1 \%$ yet.

For the sake of comparison, we compute in each model an aggregate TFP index, assuming that the data are generated by a one-sector Cobb-Douglas production function. In country $A$, the eventual increase in measured TFP is around $1 / 3$ of the actual productivity improvement in the consumption-good sector. Notice that in our proposed model, measured aggregate TFP in country $B$ is contaminated, and weakly decreasing. This comes from the fact that, due to fixed factors, returns are slightly decreasing in the economy.

\subsubsection{Numerical response to a news}

Consider first the response of the economy to a news about an abrupt increase of productivity in the consumption sector of country $A$ in period 5 . The response of the economy is shown in Fig. 2.

Let us first consider first what happens after the shock has realized (in period 5). At this stage, the consumption-good sector in country $A$ is more efficient than in country $B$. The consumption-oriented intermediate good produced in country $A$ has become cheaper relative to the consumption-oriented intermediate good produced in $B$. Due to home bias, country $A$ unsurprisingly displays higher levels of consumption, capital (not shown) and GDP. Trade is stimulated accordingly.

The interim periods take places between the announcement in period 0 and period 4 . Both economies experience expansions during interim, and display very similar responses, although the very stringent assumptions necessary to prove the perfect symmetry of the first section do not hold. As country A consumer likes the good whose productivity is announced to increase, the news has more impact in country $A$ : hours, consumption and investment increase more. Despite those differences, the two countries aggregates are pairwise positively correlated, which shows the synchronizing role of news.

In period 4, capital inputs are widely reallocated between the two countries as the shock will affect the productivity of capital the next period. One therefore observe a desynchronization of investments and outputs, while hours and consumptions stay positively correlated.

Such an abrupt increase in productivity is not what seems to happen (see Beaudry and Portier, 2006). We now look at the response of the economy to a news that productivity will start to slowly diffuse in period 5 (Fig. 3). The main difference is that the quantity anomaly disappears, and that the two countries aggregates are now always positively correlated. This experiment establishes the ability of our model to jointly explain comovements between and within countries in response to local news shocks. 

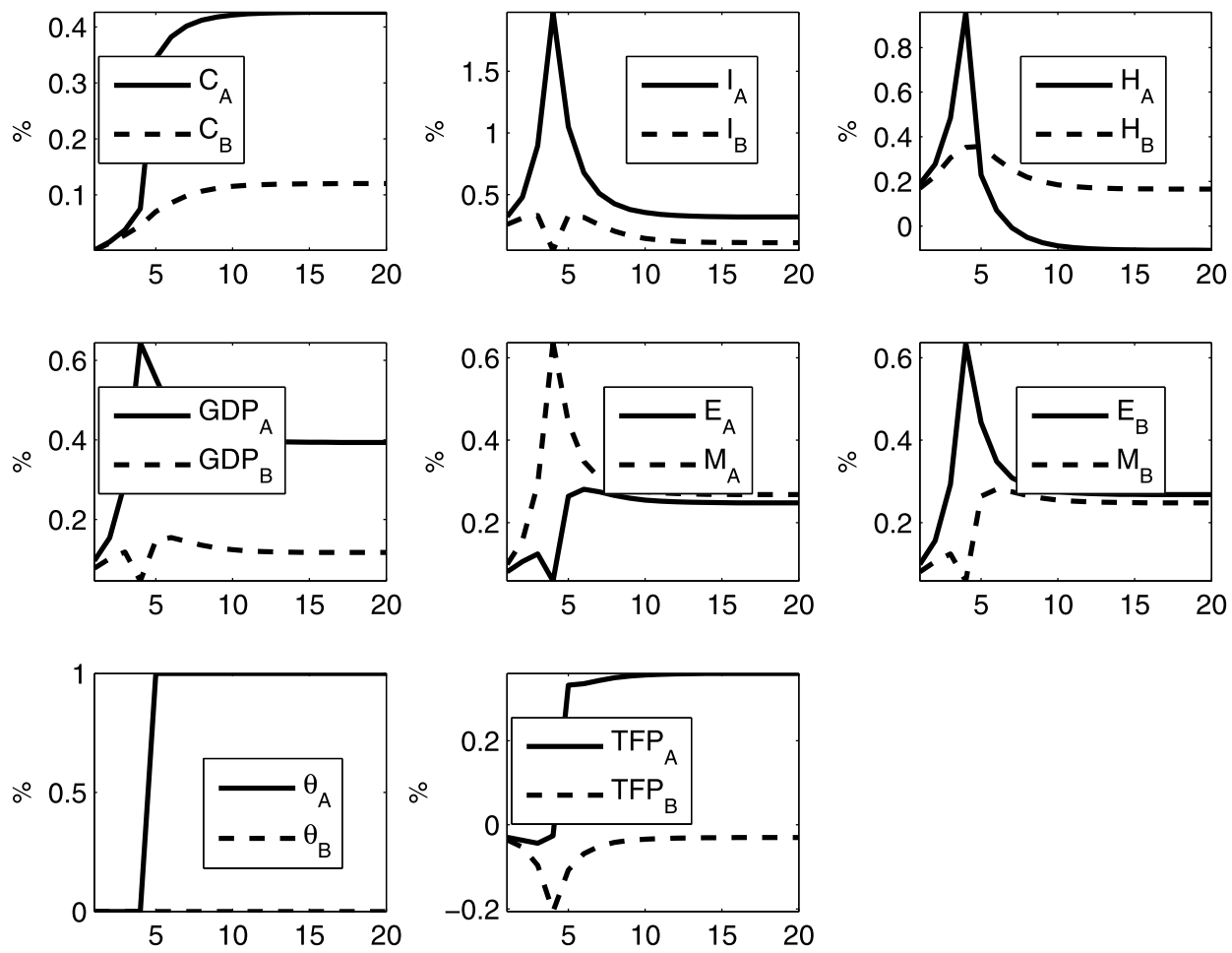

Fig. 2. Proposed model without diffusion, technological news in country $A$. In this figure, we display the response to a technological news that is specific to country $A$. In period 0 , agents learn that technology in the consumption sector of country $A$ will increase by one percent in period 5 . All variables are expressed in percentage deviation from their steady-state level. $\rho=1$ and the other parameters values are the ones of Table 1 .

Table 1

Models parameters values.

\begin{tabular}{|c|c|c|c|}
\hline & Proposed model & One-sector BKK model & Two-sector BKK model \\
\hline$N_{a}, N_{b}$ & 1 & 1 & 1 \\
\hline$a$ & 0.01 & - & 0.01 \\
\hline$b_{C}$ & 0.94 & - & 0.94 \\
\hline$b_{I}$ & 0.94 & - & 0.94 \\
\hline$b$ & - & 0.83 & - \\
\hline$\phi$ & 0.6 & - & - \\
\hline$v$ & -3.78 & - & - \\
\hline$v_{C}, v_{I}$ & -1.5 & - & -1.5 \\
\hline$v$ & -0.5 & - & - \\
\hline$\alpha_{X}$ & 0.97 & - & 0.1 \\
\hline$\beta_{X}$ & 0 & - & - \\
\hline$\alpha_{Z}$ & - & - & 0.41 \\
\hline$\alpha$ & - & $1 / 3$ & - \\
\hline$\chi$ & 0.1225 & 1 & 1 \\
\hline$\delta$ & 0.06 & 0.06 & 0.05 \\
\hline$\beta$ & 0.984 & 0.984 & 0.984 \\
\hline$\theta$ & 1 & 1 & 1 \\
\hline$\tilde{\theta}$ & 0.15 & - & 0.15 \\
\hline$\rho$ & 0.8 & 0.8 & 0.8 \\
\hline$N$ & 4 & 4 & 4 \\
\hline
\end{tabular}

\subsection{International transmission of news shocks in more standard settings}

Is the (relatively) non-standard setup of our proposed model necessary? Although we do not claim that this is the unique way of obtaining news-driven international business cycles, ${ }^{9}$ we have outlined above that one-sector models cannot generate international business cycles, and two-sector not necessarily. Here we illustrate quantitatively this claim with two

${ }^{9}$ See for example the model of Jaimovich and Rebelo (2009) and the small open-economy extension they propose in Jaimovich and Rebelo (2008). 

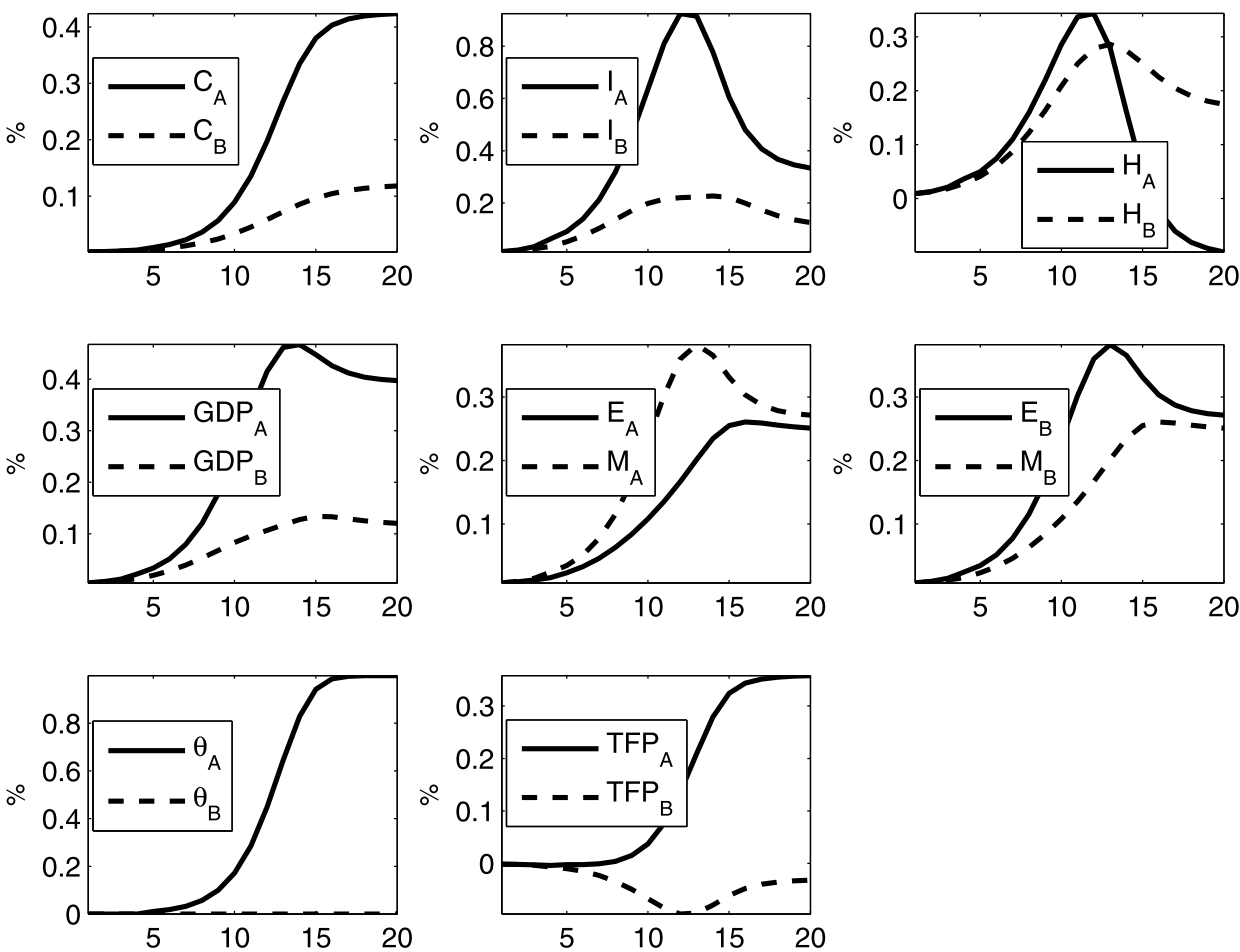

Fig. 3. Proposed model with diffusion, technological news in country $A$. In this figure, we display the response to a technological news that is specific to country $A$. In period 0 , agents learn that technology in the consumption sector of country $A$ will start diffusing in period 5 and eventually increase by one percent. All variables are expressed in percentage deviation from their steady-state level. The parameters values are the ones of Table 1.

versions of the most well accepted flex-price and complete market model of IRBC, inspired from the seminal work of Backus et al. (1994). The first version is a one-sector model, while the second is a two-sector one. We show that both models fail producing a news driven international business cycle.

\subsubsection{A one-sector BKK model}

We briefly expose the building blocks of the model.

2.2.1.1. Final goods There is one final good per country, that is used for both consumption and investment purposes. This good is obtained by combining intermediate goods produced home and abroad. Therefore, countries final good resource constraints are given by:

$$
\begin{aligned}
& C_{A, t}+I_{A, t}=\left[b Z_{A A, t}^{v}+(1-b) Z_{B A, t}^{v}\right]^{\frac{1}{v}}, \\
& C_{B, t}+I_{B, t}=\left[(1-b) Z_{A B, t}^{v}+b Z_{B B, t}^{v}\right]^{\frac{1}{v}} .
\end{aligned}
$$

Investment in each country is then used to increment the domestic stock of capital:

$$
\begin{aligned}
& K_{A, t+1}=(1-\delta) K_{A, t}+I_{A, t}, \\
& K_{B, t+1}=(1-\delta) K_{B, t}+I_{B, t} .
\end{aligned}
$$

2.2.1.2. Intermediate goods Each country $A$ and $B$ produces a country-specific intermediate good that is used domestically and exported:

$$
\begin{aligned}
& Z_{A A, t}+Z_{A B, t}=\theta_{A, t} K_{A, t}^{\alpha} H_{A, t}^{1-\alpha_{X}}, \\
& Z_{B A, t}+Z_{B B, t}=\theta_{B, t} K_{B, t}^{\alpha} H_{B, t}^{1-\alpha_{X}} .
\end{aligned}
$$

2.2.1.3. Preferences The representative household of each country has preferences over individual consumption and hours worked at all periods. We keep the Hansen-Rogerson functional form: 


$$
\begin{aligned}
& U_{A}=\sum_{t=0}^{\infty} \beta^{t}\left[\ln c_{A, t}-\chi h_{A, t}\right], \\
& U_{B}=\sum_{t=0}^{\infty} \beta^{t}\left[\ln c_{B, t}-\chi h_{B, t}\right] .
\end{aligned}
$$

\subsubsection{A two-sector BKK model}

This version is close to the proposed model, except that both production functions of intermediate goods are CobbDouglas.

2.2.2.1. Final goods There are two final goods: a final consumption good and an investment one. The consumption sector of country $A$ combines two intermediate goods, $Z_{A A}$ which is produced home and $Z_{B A}$ which is imported from country $B$, to produce the consumption good, according to the following constant returns CES aggregator:

$$
C_{A, t}=\left[b_{C} Z_{A A, t}^{\nu_{C}}+\left(1-b_{C}\right) Z_{B A, t}^{\nu_{C}}\right]^{\frac{1}{\nu_{C}}}, \quad 0<b_{C}<1 .
$$

The analogue consumption bundle for country $B$ writes

$$
C_{B, t}=\left[\left(1-b_{C}\right) Z_{A B, t}^{\nu_{C}}+b_{C} Z_{B B, t}^{\nu_{C}}\right]^{\frac{1}{\nu_{C}}} .
$$

Similarly, the final investment good in country $A$ is produced by combining two intermediate goods, $X_{A A}$ which is produced home and $X_{B A}$ which is imported from country $B$, according to

$$
I_{A, t}=\left[b_{I} X_{A A, t}^{\nu_{I}}+\left(1-b_{I}\right) X_{B A, t}^{\nu_{I}}\right]^{\frac{1}{v_{I}}}, \quad 0<b_{I}<1 .
$$

Investment in each country is then used to increment the domestic stock of capital:

$$
K_{A, t+1}=(1-\delta) K_{A, t}+I_{A, t}=(1-\delta) K_{A, t}+\left[b_{I} X_{A A, t}^{\nu_{I}}+\left(1-b_{I}\right) X_{B A, t}^{\nu_{I}}\right]^{\frac{1}{\nu_{I}}}
$$

and

$$
K_{B, t+1}=(1-\delta) K_{B, t}+I_{B, t}=(1-\delta) K_{B, t}+\left[\left(1-b_{I}\right) X_{B A, t}^{\nu_{I}}+b_{I} X_{B B, t}^{v_{I}}\right]^{\frac{1}{v_{I}}} .
$$

2.2.2.2. Intermediate goods Country $A$ produces a consumption-oriented intermediate good $Z_{A}$ using capital $K_{A}^{Z}$ and labor $H_{A}^{Z}$ according to the following Cobb-Douglas technology:

$$
Z_{A, t}=\theta_{A, t}\left(K_{A, t}^{Z}\right)^{\alpha_{z}}\left(H_{A, t}^{Z}\right)^{1-\alpha_{z}} .
$$

Country $A$ also produces a investment-oriented intermediate good $X_{A}$ using capital $K_{A}^{X}$ and labor $H_{A}^{X}$ according to the following Cobb-Douglas technology:

$$
X_{A, t}=\tilde{\theta}_{A, t}\left(K_{A, t}^{X}\right)^{\alpha_{X}}\left(H_{A, t}^{X}\right)^{1-\alpha_{X}} .
$$

In country $B$, the analogue consumption-oriented and investment-oriented intermediate goods write respectively

$$
Z_{B, t}=\theta_{B, t}\left(K_{B, t}^{Z}\right)^{\alpha_{z}}\left(H_{A, t}^{B}\right)^{1-\alpha_{z}}
$$

and

$$
X_{B, t}=\widetilde{\theta}_{B, t}\left(K_{B, t}^{X}\right)^{\alpha_{x}}\left(H_{B, t}^{X}\right)^{1-\alpha_{X}} .
$$

The total capital stock in each country is predetermined and is split between the two intermediate good sectors:

$$
\begin{aligned}
& K_{A, t}=K_{A, t}^{X}+K_{A, t}^{Z}, \\
& K_{B, t}=K_{B, t}^{X}+K_{B, t}^{Z} .
\end{aligned}
$$

2.2.2.3. Preferences The representative household of country $A$ has preferences over individual consumption and hours worked at all periods, discounts period utility at rate $\beta$ and we assume that the period utility is of the Hansen-Rogerson type:

$$
\mathcal{U}_{A}\left(c_{A, t}, h_{A, t}, \widetilde{h}_{A, t}\right)=\ln c_{A, t}-\chi\left(h_{A, t}+\widetilde{h}_{A, t}+\bar{h}_{A}\right) .
$$

The preferences of agents is country $B$ parallel those of agent in country $A$. 

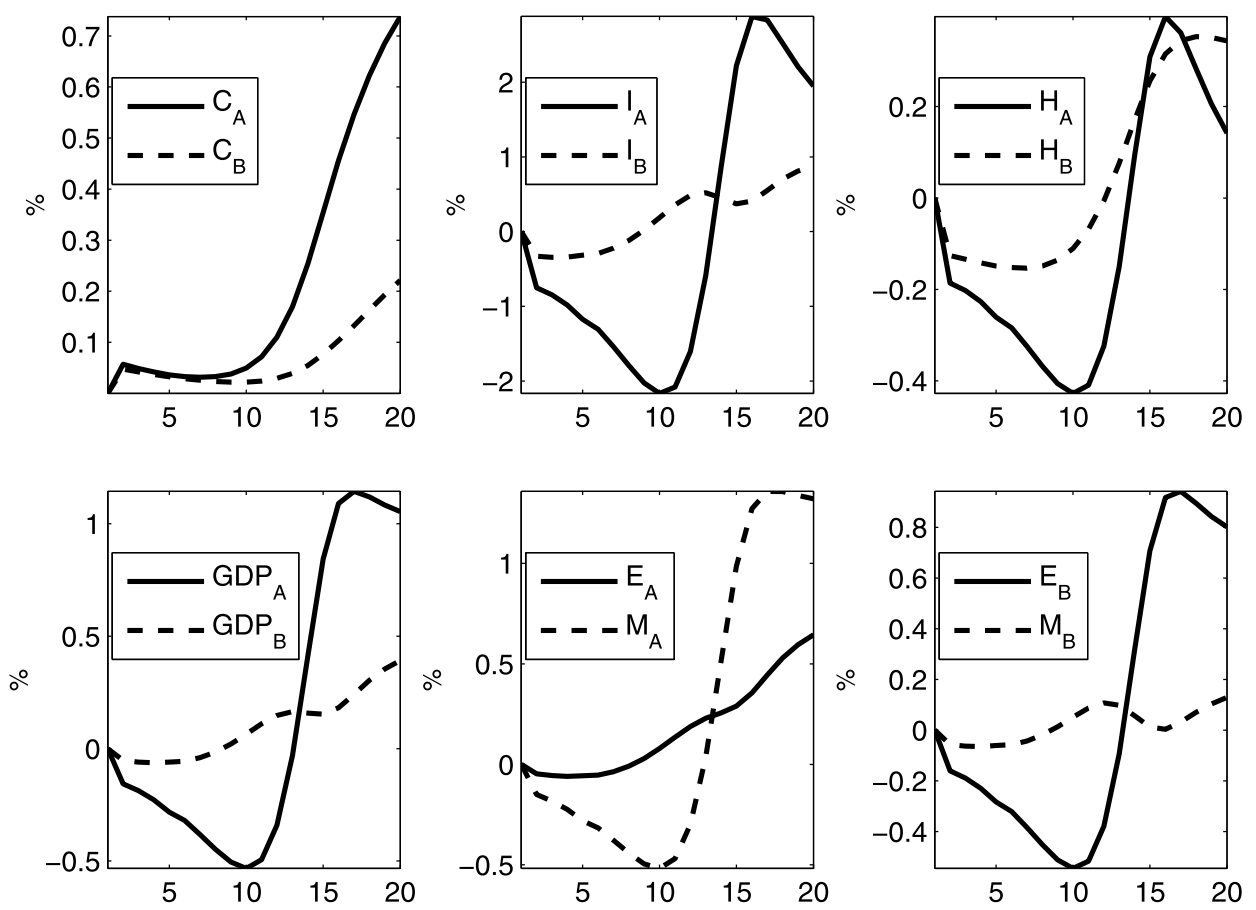

Fig. 4. One-sector BKK model, technological news in country $A$. In this figure, we display the response to a technological news that is specific to country $A$. In period 0 , agents learn that technology will start diffusing in period 5 and eventually increase by one percent in country $A$. All variables are expressed in percentage deviation from their steady-state level. The parameters values are the ones of Table 1.

\subsubsection{Numerical responses to a news shock}

The two models are calibrated to match the same steady-state properties than previously: consumption to GDP ratio is 0.7 , labor income is $2 / 3$ of GDP, imports and exports represent 25\% of GDP each and capital to annual GDP ratio is 1.25 . As previously, we assume strong complementarity between home and foreign goods (elasticity of substitution equal to 0.2 ).

The responses of these two economies to a country A technology shock that diffuses (similar to the one shown in Fig. 3 ) are displayed in Figs. 4 and 5.

Consider first the one-sector model (Fig. 4). Thanks to the diffusion process, the quantity anomaly is mitigated. Investment and hours however remain countrywide negatively correlated between periods 5 and 10 .

The main failure of this one-sector model is that the news creates a large recession in country $A$ : hours, investment and GDP decrease during interim. ${ }^{10}$ They only increase again after period 10 , where the technology starts to materialize in production. This is the typical effect of one-sector models we have highlighted in Section 2 . Agents in country $A$ want to consume more and work less as soon as they receive the news, and can do so through a reduction of investment in the interim periods. Investment recovers once productivity improves. A similar mechanism is here at work in country $B$ (as long as foreign goods enter the final good, i.e. $b<1$ ): investment in $B$ is reduced during the interim periods to finance the consumption increase. The recovery that also takes place in $B$ after the realization is explained by changes in the terms of trade, since the relative price of the intermediate good produced in country $A$ (and that $B$ imports) falls. Note that net exports are procyclical: as GDP goes down, imports decrease. The model therefore fails to produce a news driven boom that is transmitted from country $A$ to country $B$.

Consider now the two-sector model (Fig. 5). The main difference with the one-sector model is that, countrywise, hours and investment are now almost mirror images, whereas they were less negatively correlated in the one-sector model. This difference between the open-economy one-sector and two-sector models is related to properties of the closed economy one-sector and two-sector model emphasized in Section 1. We have seen that the typical interim evolution after a news shock in a one-sector model is an increase in consumption and leisure, achieved through a reduction in investment. In twosector environments where consumption and investment are different goods and the shock affects the consumption sector, this evolution needs not be optimal because capital is not easier to accumulate after the shock than before. However, in this

\footnotetext{
10 Sims (2009)'s empirical work identifies news shocks as the shock that best explains future movements in TFP among all linear combinations of innovations in a VAR (see also Barsky and Sims, 2009). The news shocks that Sims identifies in postwar US data triggers a short recession, with an initial decrease in labor input, investment and GDP. Based on Sims observations, the one-sector model's response to news appears quite reasonable. However, the response of TFP to the news shocks identified by Sims contains a very important mean reverting component, which suggested that the shock he is identifying is unlikely to be news regarding new technological opportunities. Instead, this shock is likely to be picking up endogenous responses to TFP to other disturbances. For this reason we believe that his empirical response function cannot be directly compared with those in Figs. 3 or 4 .
} 

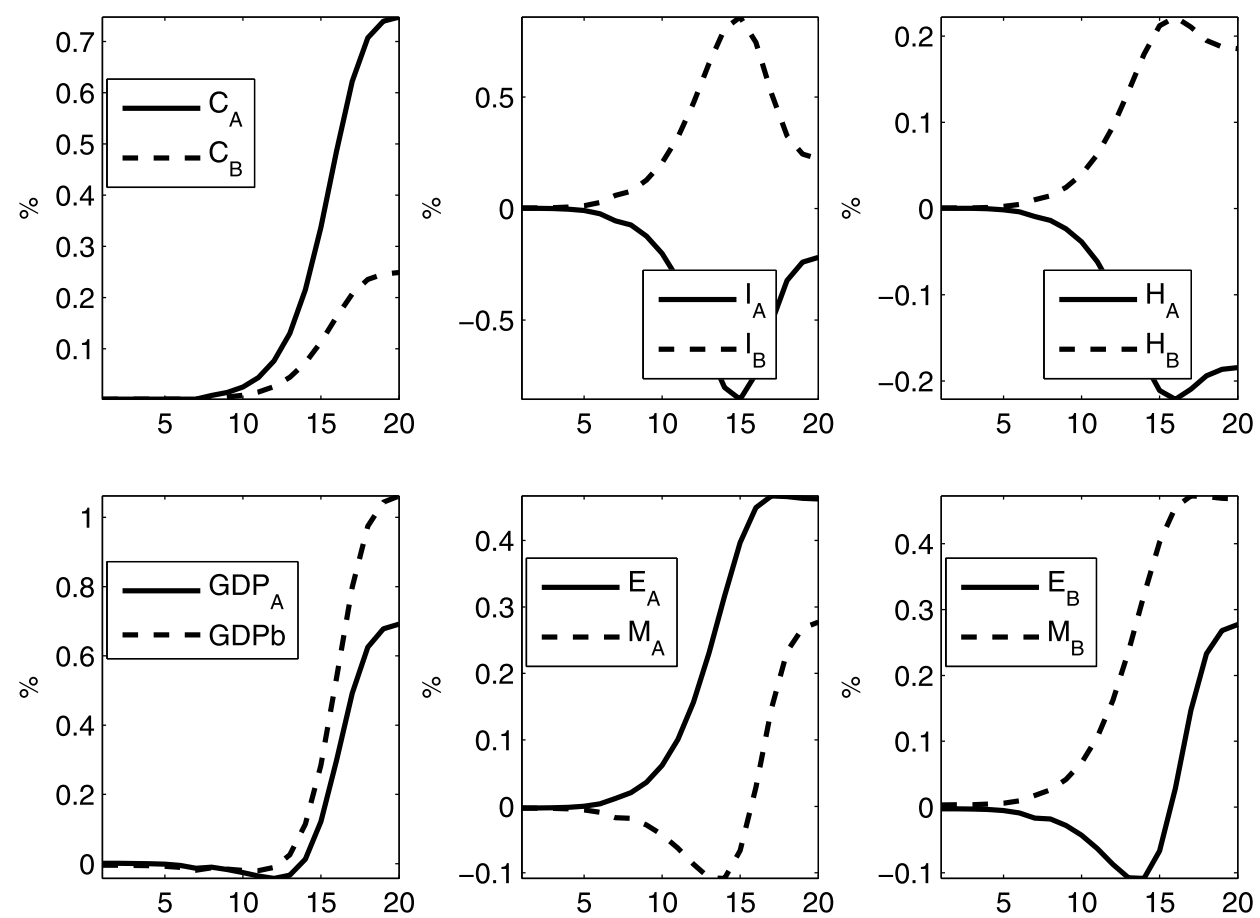

Fig. 5. Two-sector BKK model, technological news in country $A$. In this figure, we display the response to a technological news that is specific to country $A$. In period 0 , agents learn that technology will start diffusing in period 5 and eventually increase by one percent in country $A$. All variables are expressed in percentage deviation from their steady-state level. The parameters values are the ones of Table 1.

two-country two-sector model, international trade acts as an (imperfect) alternative to within country mobility of capital. Agents in country $A$ enjoy more leisure and consume (slightly) more at the expense of reduction in investment, while investment increases symmetrically in $B$. Indeed, we observe during the first ten periods movements which are similar to an input reallocation, but occur via trade in the investment-oriented intermediate good and take place in the other direction than the usual one: a larger share of the investment-oriented intermediate good produced in $A$ ends up in $B$, while shipments from $B$ to $A$ symmetrically decrease. Once productivity significantly increases in country $A$, capital shifts back to $A$ through the same mechanism. Capital accumulation is made easier, as compared to the closed economy case, in country $A$ at that stage (once again, as long as $b<1$ ) given the increased production and reduced price of investmentoriented intermediate goods in country $B$.

The inverse input reallocation is optimal in the short run in this model and not in our proposed one, because of two dimensions. First, capital can here freely be reallocated within a country between the investment and consumption sector. Second, there are no fixed factors so that returns are constant in the variable inputs.

\section{Conclusion}

In this paper, we have addressed the question of business cycle co-movements within and between countries. First, we have shown that news shocks are potentially a powerful source of joint co-movements across countries. We then have proposed a two-country two-sector model that allows for news shocks to propagate and generate international business cycles. We have also shown that canonical two-country RBC model were not able to generate news-driven national and international business cycles.

Two extensions of this analysis are work in progress. First, we show in Beaudry et al. (2010) that technological news are indeed found in the data, as well in the U.S. and in Germany. We also show that those news do propagate to Canada (for the U.S.) and Austria (for Germany), generating international business cycles. Second, we need to investigate whether a model along the lines presented here also replicates unconditional moments of international business cycles when other shocks are introduced in the analysis.

\section{Appendix A. Restrictions on preferences}

Preferences $U(\cdot, \cdot)$ are defined over consumption and leisure, with $U_{1}>0$ and $U_{2}>0$. The function $U$ is assumed to be concave, so that we have the restrictions $U_{11} \leqslant 0, U_{22} \leqslant 0$ and $\left(U_{12}\right)^{2} \leqslant U_{11} U_{22}$. We further assume that preferences are compatible with balanced growth and take the form 


$$
\left\{\begin{array}{l}
\text { (a) } \left.U(C, 1-H)=\frac{C^{1-\sigma}}{1-\sigma} \times v(1-H) \quad \text { with } 0 \leqslant \sigma<1\left(\text { case } a_{1}\right) \text { or } \sigma>1 \text { (case } \mathrm{a}_{2}\right), \\
\text { (b) } U(C, 1-H)=\log C+v(1-H) .
\end{array}\right.
$$

Leisure being a good and concavity imply the following restrictions on $v: v^{\prime}>0, v^{\prime \prime}<0$ and $\left(v^{\prime}\right)^{2} \leqslant-\sigma /(1-\sigma) v v^{\prime \prime}$ in case $\left(\mathrm{a}_{1}\right) ; v^{\prime}<0, v^{\prime \prime} \geqslant 0$ and $\left(v^{\prime}\right)^{2} \leqslant-\sigma /(1-\sigma) v v^{\prime \prime}$ in case $\left(\mathrm{a}_{2}\right) ; v^{\prime}>0$ and $v^{\prime \prime} \leqslant 0$ in case (b).

We first show that consumption and leisure are normal goods.

Definition 1. Consider the following maximization problem: $\max U(C, 1-H)$ s.t. $p C \leqslant Y+w H$ where $Y$ is non labor income. Let $C^{\star}(Y, w, p)$ and $H^{\star}(Y, w, p)$ be the solutions to this problem. Consumption and leisure are normal goods if $\partial C^{\star} / \partial Y \geqslant 0$ and $\partial H^{\star} / \partial Y \leqslant 0$.

Let us derive the restrictions on $U$ implied by this definition. First-order conditions of the problem $\max U(C, 1-H)$ s.t. $p C \leqslant Y+w H$ are:

$$
\begin{aligned}
& w U_{1}=p U_{2}, \\
& p C-w H=Y .
\end{aligned}
$$

Fully differentiating those two equations, we get

$$
\begin{aligned}
& \left(p U_{22}-w U_{12}\right) d H=\left(p U_{21}-w U_{11}\right) d C, \\
& p d C-w d H=d Y .
\end{aligned}
$$

Using the fact that $w / p=U_{2} / U_{1}$ at the optimum, those two equations become

$$
\begin{aligned}
& \left(U_{1} U_{22}-U_{2} U_{12}\right) d H=\left(U_{1} U_{21}-U_{2} U_{11}\right) d C, \\
& d C-\frac{U_{2}}{U_{1}} d H=\frac{1}{p} d Y .
\end{aligned}
$$

Denote

$$
\begin{aligned}
& \alpha_{1}=U_{1} U_{21}-U_{2} U_{11}, \\
& \alpha_{2}=U_{1} U_{22}-U_{2} U_{12} .
\end{aligned}
$$

We restrict attention to cases in which the maximization problem has a unique solution, and therefore exclude the case $\alpha_{1}=\alpha_{2}=0$. When $\alpha_{2}=0$, the two previous equations imply $d C=0$ and $d H<0$, which satisfies normality. When $\alpha_{1}=0$, the two previous equations imply $d C>0$ and $d H=0$, which satisfies normality. When $\alpha_{1} \neq 0$ and $\alpha_{2} \neq 0$, those two equations imply

$$
\left(1-\frac{U_{2}}{U_{1}} \frac{\alpha_{1}}{\alpha_{2}}\right) d C=\frac{1}{p} d Y .
$$

Rearranging terms, we obtain

$$
\begin{aligned}
& d H=\frac{\alpha_{1}}{\alpha_{2}} d C, \\
& \frac{U_{1} \alpha_{2}-U_{2} \alpha_{1}}{U_{1} \alpha_{2}} d C=\frac{1}{p} d Y .
\end{aligned}
$$

Normality requires that consumption and leisure move in opposite direction, and that consumption comoves positively with income. From Eqs. (A.1) and (A.2), we get that conditions for normality are $\frac{\alpha_{1}}{\alpha_{2}}<0$ and $\frac{U_{1} \alpha_{2}-U_{2} \alpha_{1}}{U_{1} \alpha_{2}}>0$.

Eq. (A.1) implies that $d H / d C<0$ if and only if (i) $\alpha_{1}>0$ and $\alpha_{2}<0$ or (ii) $\alpha_{1}<0$ and $\alpha_{2}>0$. Consider first case (i). It is easy to check that $\alpha_{2}<0$ if and only if $U_{12}>\frac{U_{1} U_{22}}{U_{2}}$ and that $\alpha_{1}>0$ if and only if $U_{12}>\frac{U_{2} U_{11}}{U_{1}}$.

Consider now case (ii). $\alpha_{1}<0$ and $\alpha_{2}>0$ are equivalent to $U_{12}<\frac{U_{1} U_{22}}{U_{2}}$ and $U_{12}<\frac{U_{2} U_{11}}{U_{1}}$. As the four members of those two inequalities are negative, these two inequalities imply (by multiplying term by term) $U_{12}^{2}>U_{11} U_{22}$, which violates concavity of $U$. Case (ii) is therefore not admissible. Necessary and sufficient conditions for normality are therefore (A.3) (case $\alpha_{2}=0$ ) or (A.4) (case $\alpha_{1}=0$ ) or $\left\{(\right.$ A.5), (A.6) $\}$ (case $\alpha_{1} \neq 0$ and $\alpha_{2} \neq 0$ ), with

$$
\begin{aligned}
& U_{1} U_{22}=U_{2} U_{12}, \\
& U_{1} U_{21}=U_{2} U_{11}, \\
& U_{12}>\frac{U_{1} U_{22}}{U_{2}}, \\
& U_{12}>\frac{U_{2} U_{11}}{U_{1}} .
\end{aligned}
$$


Let us now check that consumption and leisure are normal goods for balanced growth compatible preferences. In case (b), $U(C, 1-H)=\log C+v(1-H)$, one can check easily that (A.3) is satisfied.

In case $\left(\mathrm{a}_{1}\right), 0 \leqslant \sigma<1, U_{12}=C^{-\sigma} v^{\prime}$ is positive. When $U_{12}>0$, one can check that $\alpha_{1}>0$ and $\alpha_{2}<0$, so that (A.5) and (A.6) hold. Therefore, $d H / d C<0$ and $d C / d Y>0$.

In case $\left(\mathrm{a}_{2}\right), \sigma>1$, let us check that Eqs. (A.5) and (A.6) are satisfied. Consider first (A.5). We have $\frac{U_{1} U_{22}}{U_{2}}=\frac{C^{-\sigma} v v^{\prime \prime}}{v^{\prime}}$ and $U_{12}=C^{-\sigma} v^{\prime}$. Comparing those two expressions which are the left and right side of (A.5), we can see that (A.5) holds if and only if $\left(v^{\prime}\right)^{2} \leqslant v v^{\prime \prime}$. A restriction for concavity of $U$ is $\left(v^{\prime}\right)^{2} \leqslant-\sigma /(1-\sigma) v v^{\prime \prime}$. In case $\left(\mathrm{a}_{2}\right),-\sigma /(1-\sigma)>1$, so that $\left(v^{\prime}\right)^{2} \leqslant v v^{\prime \prime}$ and therefore (A.5) holds. Consider now condition (A.6). It writes $-\sigma /(1-\sigma)>1$ which always holds in case $\left(\mathrm{a}_{2}\right)$.

Therefore, balanced growth compatible preferences guaranty the normality of consumption and leisure. Note that with such preferences (A.4) never holds.

\section{Appendix B. Proof of the synchronization result}

We first prove the existence of a solution which is symmetric during the interim periods. Under Assumption (A), the closed economy problem has a unique solution for any initial condition $K_{0}$ : a vector $\left(\mathcal{K}_{t}^{c}, H_{t}^{c}, C_{t}^{c}, K_{t+1}^{c}, \lambda_{t}^{c}\right.$, $\left.\nu_{t}^{c}\right)$ which satisfies

$$
\begin{aligned}
& K_{t+1}^{c}=(1-\delta) K_{t}^{c}+F\left(\mathcal{K}_{t}^{c}, H_{t}^{c} ; \theta_{t}\right)-C_{t}^{c}, \\
& K_{t}^{c}=\mathcal{K}_{t}^{c}, \\
& \lambda_{t}^{c}=E_{t}\left[\lambda_{t+1}^{c}(1-\delta)+v_{t+1}^{c}\right], \\
& U_{1}\left(C_{t}^{c}, 1-H_{t}^{c}\right)=\lambda_{t}^{c}, \\
& \frac{U_{2}\left(C_{t}^{c}, 1-H_{t}^{c}\right)}{F_{2}\left(\mathcal{K}_{t}^{c}, H_{t}^{c} ; \theta_{t}\right)}=\lambda_{t}^{c}, \\
& F_{1}\left(\mathcal{K}_{t}^{c}, H_{t}^{c} ; \theta_{t}\right)=\frac{v_{t}^{c}}{\lambda_{t}^{c}} .
\end{aligned}
$$

Conditions (B.3) to (B.6) are equivalent to conditions (3) to (6). (B.1) and (B.2) can be rewritten as

$$
\begin{aligned}
& \Longleftrightarrow \quad K_{t+1}^{c}=(1-\delta) K_{t}^{c}+\pi\left[F\left(\mathcal{K}_{t}^{c}, H_{t}^{c} ; \theta_{t}\right)-C_{t}^{c}\right]+(1-\pi)\left[F\left(\mathcal{K}_{t}^{c}, H_{t}^{c} ; \theta_{t}\right)-C_{t}^{c}\right], \\
& \Longleftrightarrow K_{t}^{c}=\pi \mathcal{K}_{t}^{c}+(1-\pi) \mathcal{K}_{t}^{c} .
\end{aligned}
$$

Hence, between periods 0 and $T-1$, the allocation $\left(K_{J, t}, H_{J, t}, C_{J, t}\right)=\left(\mathcal{K}_{t}^{c}, H_{t}^{c}, C_{t}^{c}\right)$ for $J=A, B, K_{t+1}=K_{t+1}^{c}$ and $\left(\lambda_{t}, v_{t}\right)=$ $\left(\lambda_{t}^{c}, v_{t}^{c}\right)$ satisfies the nine conditions (1) to (6). This proves the existence of a solution of the two-country problem with initial capital per capita $K_{0}$. By construction, this equilibrium allocation is perfectly symmetric between 0 and $T-1$. At date $T$, the shock materializes in one country which implies $\theta_{A, t} \neq \theta_{B, t}$. The duplication argument cannot therefore apply any longer.

We now prove the uniqueness of this solution.

Assume that another solution $\left(\hat{K}_{A, t}, \hat{H}_{A, t}, \hat{C}_{A, t}, \hat{K}_{B, t}, \hat{H}_{B, t}, \hat{C}_{B, t}, \hat{K}_{t+1}, \hat{\lambda}_{t}, \hat{v}_{t}\right)$ exists, given the initial per capita stock of world capital $\hat{K}_{0}$. By definition, this allocation is such that at date 0

$$
\begin{aligned}
& \hat{K}_{1}=(1-\delta) \hat{K}_{0}+\pi\left[F\left(\hat{K}_{A, 0}, \hat{H}_{A, 0} ; \theta_{A, 0}\right)-\hat{C}_{A, 0}\right]+(1-\pi)\left[F\left(\hat{K}_{B, 0}, \hat{H}_{B, 0} ; \theta_{B, 0}\right)-\hat{C}_{B, 0}\right], \\
& \hat{K}_{0}=\pi \hat{K}_{A, 0}+(1-\pi) \hat{K}_{B, 0}, \\
& \hat{\lambda}_{0}=E_{0}\left[(1-\delta) \hat{\lambda}_{1}+\hat{v}_{1}\right]
\end{aligned}
$$

and for $J=A, B$

$$
\begin{aligned}
& U_{1}\left(\hat{C}_{J, 0}, 1-\hat{H}_{J, 0}\right)=\hat{\lambda}_{0}, \\
& \frac{U_{2}\left(\hat{C}_{J, 0}, 1-\hat{H}_{J, 0}\right)}{F_{2}\left(\hat{K}_{J, 0}, \hat{H}_{J, 0} ; \theta_{J, 0}\right)}=\hat{\lambda}_{0}, \\
& F_{1}\left(\hat{K}_{J, 0}, \hat{H}_{J, 0} ; \theta_{J, 0}\right)=\frac{\hat{v}_{0}}{\hat{\lambda}_{0}} .
\end{aligned}
$$

Out of this solution, we can construct two distinct autarkic equilibrium allocations for countries $A$ and $B$. To begin with, allocate $\hat{K}_{A, 0}$ units of capital per capita to economy $A$ and $\hat{K}_{B, 0}$ to economy B. Condition (B.8) ensures that this split of the initial world stock of capital $\hat{K}_{0}$ is feasible. Assume that each economy uses all available capital. Using Eqs. (B.9) to (B.12), we see that both vectors $\left(\hat{K}_{A, 0}, \hat{H}_{A, 0}, \hat{C}_{A, 0}, \hat{\lambda}_{0}, \hat{v}_{0}\right)$ and $\left(\hat{K}_{B, 0}, \hat{H}_{B, 0}, \hat{B}_{A, 0}, \hat{\lambda}_{0}, \hat{v}_{0}\right)$ satisfy conditions (8) to (12). Finally, capital accumulated in the two autarkic economies, $(1-\delta) \hat{K}_{A, 0}+F\left(\hat{K}_{A, 0}, \hat{H}_{A, 0} ; \theta_{A, 0}\right)-\hat{C}_{A, 0}$ and $(1-\delta) \hat{K}_{B, 0}+F\left(\hat{K}_{B, 0}, \hat{H}_{B, 0} ; \theta_{B, 0}\right)-$ 
$\hat{C}_{B, 0}$, add up to $\hat{K}_{1}$, according to (B.7) and (B.8). No reallocation of capital is necessary at the beginning of period 1 , meaning that this allocation of the two-country economy is indeed the juxtaposition of two autarkic economies.

We have therefore constructed two solutions of the single-country problem (7) to (12). Assumption (A) therefore implies that these solutions are identical to the first solution constructed

$$
\left\{\begin{array}{l}
\hat{K}_{A, t}=\hat{K}_{B, t}=\mathcal{K}_{t}^{c}, \\
\hat{H}_{A, t}=\hat{H}_{B, t}=H_{t}^{c}, \\
\hat{C}_{A, t}=\hat{C}_{B, t}=C_{t}^{c}, \\
(1-\delta) \hat{K}_{A, 0}+F\left(\hat{K}_{A, 0}, \hat{H}_{A, 0} ; \theta_{A, 0}\right)-\hat{C}_{A, 0}=(1-\delta) \hat{K}_{B, 0}+F\left(\hat{K}_{B, 0}, \hat{H}_{B, 0} ; \theta_{B, 0}\right)-\hat{C}_{B, 0}=K_{t+1}^{c}, \\
\hat{\lambda}_{t}=\lambda_{t}^{c}, \\
\hat{v}_{t}=v_{t}^{c} .
\end{array}\right.
$$

In other words, there exists a unique solution and this solution is symmetrical.

\section{References}

Ambler, S., Cardia, E., Zimmermann, C., 2004. International business cycles: What are the facts? Journal of Monetary Economics 51 (2), $257-276$.

Backus, D., Kehoe, P., Kydl, F., 1994. Dynamics of the trade balance and the terms of trade: The J-curve? American Economic Review 84 (1), $84-103$.

Backus, D., Kehoe, P., Kydl, F., 1995. International business cycles: Theory and evidence. In: Cooley, T. (Ed.), Frontiers of Business Cycle Research. Princeton University Press, Princeton, NJ, Chap. 11, pp. 331-356.

Barsky, R., Sims, E., 2009. News shocks. NBER working paper No. 15312.

Beaudry, P., Lucke, B., 2009. Letting different views about business cycles compete. In: Acemoglu, D., Rogoff, K., Woodford, M. (Eds.), NBER Macroeconomics Annual, vol. 24, pp. 413-455.

Beaudry, P., Portier, F., 2004. An exploration into Pigou's theory of cycles. Journal of Monetary Economics 51 (6), $1183-1216$.

Beaudry, P., Portier, F., 2005. The "News View" of economic fluctuations: Evidence from aggregate Japanese data and sectoral US data. Journal of the Japanese and International Economies 19 (4), 635-652.

Beaudry, P., Portier, F., 2006. News, stock prices and economic fluctuations. The American Economic Review 96 (4), $1293-1307$.

Beaudry, P., Portier, F., 2007. When can changes in expectations cause business cycle fluctuations in neo-classical settings? Journal of Economic Theory 135 (1), 458-477.

Beaudry, P., Collard, F., Portier, F., 2006. Gold rush fever in business cycles. NBER working paper No. 12710.

Beaudry, P., Dupaigne, M., Portier, F., 2010. The international propagation of news shocks. Oxford University and Toulouse School of Economics. Mimeo.

Christiano, L., Ilut, C., Motto, R., Rostagno, M., 2008. Monetary policy and a stock market boom-bust cycle. ECB working paper No. 955.

Corsetti, G., Dedola, L., Leduc, S., 2008. International risk sharing and the transmission of productivity shocks. Review of Economic Studies 75 (2), $443-473$.

Den Haan, W.J., Kaltenbrunner, G., 2009. Anticipated growth and business cycles in matching models. Journal of Monetary Economics 56 (3), $309-327$.

Haertel, T., Lucke, B., 2007. New evidence on news-driven business cycles. Economics Discussion Papers (2007-27), available at http://www.economicsejournal.org/economics/discussionpapers/2007-27.

Jaimovich, N., Rebelo, S., 2008. News and business cycles in open economies. Journal of Money, Credit and Banking 40 (8), $1699-1711$.

Jaimovich, N., Rebelo, S., 2009. Can news about the future drive the business cycle? American Economic Review 99 (4), $1097-1118$.

Kydland, F., Prescott, E.C., 1982. Time to build and aggregate fluctuations. Econometrica 50 (6), 1345-1370.

Schmitt-Grohé, S., Uribe, M., 2008. What's news in business cycles. NBER working paper No. 14215.

Sims, E., 2009. Expectations driven business cycles: An empirical evaluation. University of Notre-Dame. Mimeo.

Wen, Y., 2007. By force of demand: Explaining international comovements. Journal of Economic Dynamics and Control 31 (1), 1-23. 